\title{
Biomarkers for invasive aspergillosis: the challenges continue
}

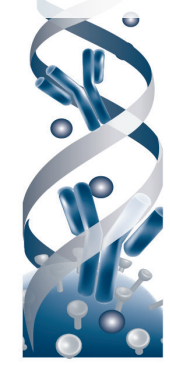

The incidence of invasive aspergillosis (IA), an opportunistic infection in immunocompromised individuals, is rising, but its early diagnosis remains challenging and treatment options are limited. Hence there is an urgent need to improve existing diagnostic procedures as well as develop novel approaches. The clinical usefulness of galactomannan and $\beta$-D-glucan, widely used assays detecting cell-wall antigens of Aspergillus, is unclear and depends on clinicians' awareness of their practical limitations. This leaves room for new methods that utilize genomic, proteomic and metabolomics approaches as well as novel detection procedures, for example pointof-care lateral-flow devices. Each of these strategies has its own limitations and it is likely that a combination of methods will be required to achieve optimal performance for the diagnosis of IA and subsequent appropriate patient management.

Keywords: antifungal agents $\bullet$ Aspergillus $\bullet \beta$-D-glucan $\bullet$ conidium $\bullet$ ELISA $\bullet$ fungal infection • galactomannan $\bullet$ immunosuppression $\bullet$ invasive aspergillosis $\bullet$ matrix-assisted laser desorption ionization-TOF • quantitative PCR • siderophore

\section{Background}

Invasive fungal infections (IFIs) are a major source of morbidity and mortality in immunocompromised individuals, especially in hematological patients with prolonged periods of neutropenia [1]. They pose considerable challenges to early diagnosis and effective patient management, where in addition to prophylaxis, early and appropriate initiation of antifungal therapy is key to a favorable clinical outcome [2]. Many centers use an empirical approach to patient management and antifungal treatment is commenced when there are clinical signs and symptoms of invasive disease, even in the absence of fungal pathogen identification. This is likely to lead to the treatment of patients who do not have invasive fungal disease. By contrast, a diagnostic-driven approach combines biomarker detection and imaging techniques to direct therapy and aim for a rapid assessment of the likelihood of IFI. This approach aims to treat only patients with evidence of IFI, with treatment withheld and IFI excluded in patients with negative diagnostic test results. The success of such an approach is heavily reliant on the early availability of biomarker assays and imaging services, and its efficacy has not yet been established.

Diagnosis is generally based on a combination of compatible clinical findings in a patient with risk factors together with histopathological evidence of invasion, serological detection of antibodies or antigens, radiological data and, less frequently, isolation of the pathogen. Methods include direct microscopy, radiographic imaging such as x-rays and CT scans [3], biomarker analysis using molecular techniques [4], attempts to grow fungi taken from sterile culture and bronchoalveolar lavage (BAL) fluid as well as nonculture-based detection of fungal antigens in blood, plasma, serum or BAL fluid [1].

The European Organisation for Research and Treatment of Cancer/Mycoses Study Group (EORTC/MSG) has published consensus criteria for defining proven, probable and possible IFIs. Under the original guide-
Gemma Johnson', Arianna Ferrini², Stephen K Dolan ${ }^{3}$, Tania Nolan ${ }^{4}$, Samir Agrawal', Sean Doyle ${ }^{3}$ \& Stephen A Bustin*,5

'Blizard Institute, Queen Mary University of London, London, UK

${ }^{2}$ Clinical Pathology, Barts Health NHS Trust, London, UK

${ }^{3}$ Department of Biology, Nationa University of Ireland Maynooth,

County Kildare, Ireland

${ }^{4}$ Sigma Custom Products, Haverhill, Suffolk, UK

${ }^{5}$ Postgraduate Medical Institute, Faculty of Health, Social Care \& Education, Anglia Ruskin University, Bishop Hall Lane, Chelmsford, Essex, CM1 1SQ, UK *Author for correspondence: stephen.bustin@anglia.ac.uk 
lines, IFI was proven if a fungus was detected by histological analysis or culture of a specimen of tissue taken from a site of disease [5]. Probable and possible IFI required:

- A host factor that identified the patients at risk;

- Clinical signs and symptoms consistent with the disease entity;

- Mycological evidence from culture and microscopic analysis as well as from indirect tests.

However, it became apparent that the definitions needed refinement and extension to recipients of solidorgan transplants and patients with primary immunodeficiencies. This resulted in the revised definitions, which adopted the term invasive fungal disease (IFD), modified the criteria for proven and probable IFD to reflect advances in indirect tests and defined the category of possible IFD more strictly to include only cases that are highly likely to be caused by a fungal etiology, although mycological evidence is lacking [6].

A serious practical problem with this classification is that testing requires the use of lung biopsies and BALs; however, at-risk patients are usually characterized by thrombocytopenia and neutropenia, which precludes the use of such invasive procedures. Since prompt initiation of therapy is a critical prognostic factor [7], this frequently means starting empirical antifungal therapy. Furthermore, blood or other body fluids are rarely positive for fungal pathogens [8], particularly when blood samples are taken after the start of antimicrobial therapy.

Hence there has been a concerted effort to identify alternative procedures for the future diagnosis of mycoses, not all of which have entered clinical practice. They include the targeting of fungal antigens by ELISA or lateral flow devices (LFDs) [9], detection of siderophores [10] and amplification of fungal nucleic acids from tissue and body fluids [11] as well as application of matrix-assisted laser desorption ionization TOF mass spectrometry (MALDI-TOF MS) [12] (Table 1).

One interesting development concerns the use of a combination of antibody-based technology and the PCR in the proximity ligation or extension assay (PLA or PEA) (Figure 1). PLA is an innovative immunoassay platform that combines the exquisite sensitivity and dynamic range of real time quantitative PCR (qPCR) with the specificity of antibody-based detection of proteins and other analytes to allow accurate quantification of antigens in blood and tissue samples [13]. PLA offers several advantages over traditional ELISAs, including better sensitivity ( $50-500$-fold) and broader dynamic range ( $\sim 5$ vs $2.5 \operatorname{logs}$ ), simpler workflow (requiring no wash steps) and faster time to results (1.5-2 vs $5 \mathrm{~h}$ ). The assay is being used to detect Aspergillus-specific $\mathrm{N}$-linked glycoprotein antigens that are secreted constitutively at the hyphal apex in actively growing organisms [14] and is currently under development in one of the author's laboratory (Bustin).

\section{Invasive aspergillosis}

Fungi of the genus Aspergillus are the cause of a wide range of diseases that range from allergic reactions to disseminated invasive disease in immunocompromised patients. Invasive aspergillosis (IA), the most common invasive mould disease worldwide, is usually seen in the lungs (pulmonary aspergillosis), but can also disseminate to other tissues, including the CNS, sinuses, bone, heart, kidney, eye, blood and skin [15]. IA is caused primarily by inhalation of the ubiquitous Aspergillus fumigatus, although there are other pathogens in this genus, which include the morphologically distinct A. flavus, $A$. terreus, $A$. niger and $A$. nidulans, all of which can be agents of IA [16]. The small diameter of their conidia, which range from 2-5 $\mu \mathrm{m}$ depending on the species, allows them to reach the lung alveoli. This rarely has any adverse effect on immunocompetent individuals, since innate immune mechanisms remove the conidia fairly efficiently [17]. In immunosuppressed patients, on the other hand, inhaled conidia adhere to airway epithelial cells or pulmonary macrophages, are internalized and undergo germination. Hyphal growth occurs by apical extension, with their angiogenic properties giving the fungus access to the vascular compartment (reviewed in [18]). This results in the dissemination and invasion of deep tissues, where they can cause severe and usually fatal invasive infections. Although the introduction of new noninvasive tests, combined with more effective and better-tolerated antifungal agents, has resulted in lower mortality rates associated with IA, this disease continues to have substantial attributable mortality combined with a major impact on hospital resource use [19].

\section{Cell culture \& direct microscopy}

The traditional method for diagnosing IA involves culturing of Aspergilli and using phenotype-based identification schemes such as shape, size, color, ornamentation and/or mode of attachment to distinguish Aspergillus species [20]. While relatively low cost and having the advantage of allowing additional testing, for example for antibiotic resistance, its slowness (2-5 days minimum), requirement for a surgical biopsy of a sterile site and potential for contamination make it less than ideal for early diagnosis [21]. Furthermore, although a positive culture result identifies an infection, it could be a result of colonization in the absence of invasive infec- 


\begin{tabular}{|c|c|c|}
\hline Assay & Advantages & Disadvantages \\
\hline \multirow{3}{*}{$\begin{array}{l}\text { Platelia }{ }^{\mathrm{TM}} \text { Aspergillus EIA } \\
\text { (Bio-Rad, France) }\end{array}$} & Rapid & Variable sensitivity \\
\hline & Aspergillus specific & Low positive-predictive value \\
\hline & Microtiter-based ELISA & \\
\hline \multirow{2}{*}{$\beta$-D-glucan EIA } & Rapid & Low sensitivity \\
\hline & Panfungal & Low positive-predictive value \\
\hline \multirow[t]{6}{*}{ Siderophore detection } & Simple & Species specificity to be determined \\
\hline & Rapid & \\
\hline & Detects actively growing fungi & \\
\hline & Microtiter-based format & \\
\hline & High throughput & \\
\hline & $\begin{array}{l}\text { Potentially noninvasive } \\
\text { (compatible with urine matrix) }\end{array}$ & \\
\hline \multirow[t]{8}{*}{ Lateral flow devices } & Simple & Qualitative/semiquantitative \\
\hline & Rapid & Relatively insensitive \\
\hline & Cheap & Readout not easily automated \\
\hline & Portable & \\
\hline & Long shelf-life & \\
\hline & Robust & \\
\hline & Medium-high throughput & \\
\hline & User-friendly & \\
\hline \multirow[t]{7}{*}{$P C R / q P C R$} & Simple & Highly variable results \\
\hline & Sensitive & Potential for detecting false positives \\
\hline & Early detection & Not easily used at POC \\
\hline & Species specific & No information on viability \\
\hline & Quantitative (qPCR) & No information on active growth \\
\hline & High throughput (qPCR) & Contamination potential (PCR) \\
\hline & Automated readout (qPCR) & Need to extract DNA \\
\hline \multirow[t]{5}{*}{ MALDI-TOF MS } & Rapid & Culture dependent \\
\hline & High throughput & Requires a reference database \\
\hline & Cheap running costs & Cost of instrument \\
\hline & Easy sample preparation & \\
\hline & Reliable identification & \\
\hline
\end{tabular}

tion. Also, culturing is not a sensitive detection method: most cases proven or probable by serum- or BALpositive ELISA are not culture positive [22] and sensitivity in a rabbit model of IA ranged from $50-100 \%$, interestingly dependent on the infecting Aspergillus species [23]. On the other hand, culture-positive rabbits treated with amphotericin B became culture-negative, whereas BALs remained positive for galactomannan (GM) and PCR, suggesting that GM or PCR positivity are not necessarily the equivalent of fungal viability, but nevertheless allow pathogen identification even after antifungal therapy has been started [23].

Histological examination of infected tissue remains the 'gold standard' for diagnosis, although obtaining tissue may be impractical owing to the risks associated with the underlying disease. A Gram's stain or Grocott's methenamine silver stain may be carried out to identify any fungal elements, with direct microscopic detection of Aspergillus hypha in clinical specimens confirming a likely role in infection [24]. Cells from bronchial wash- 


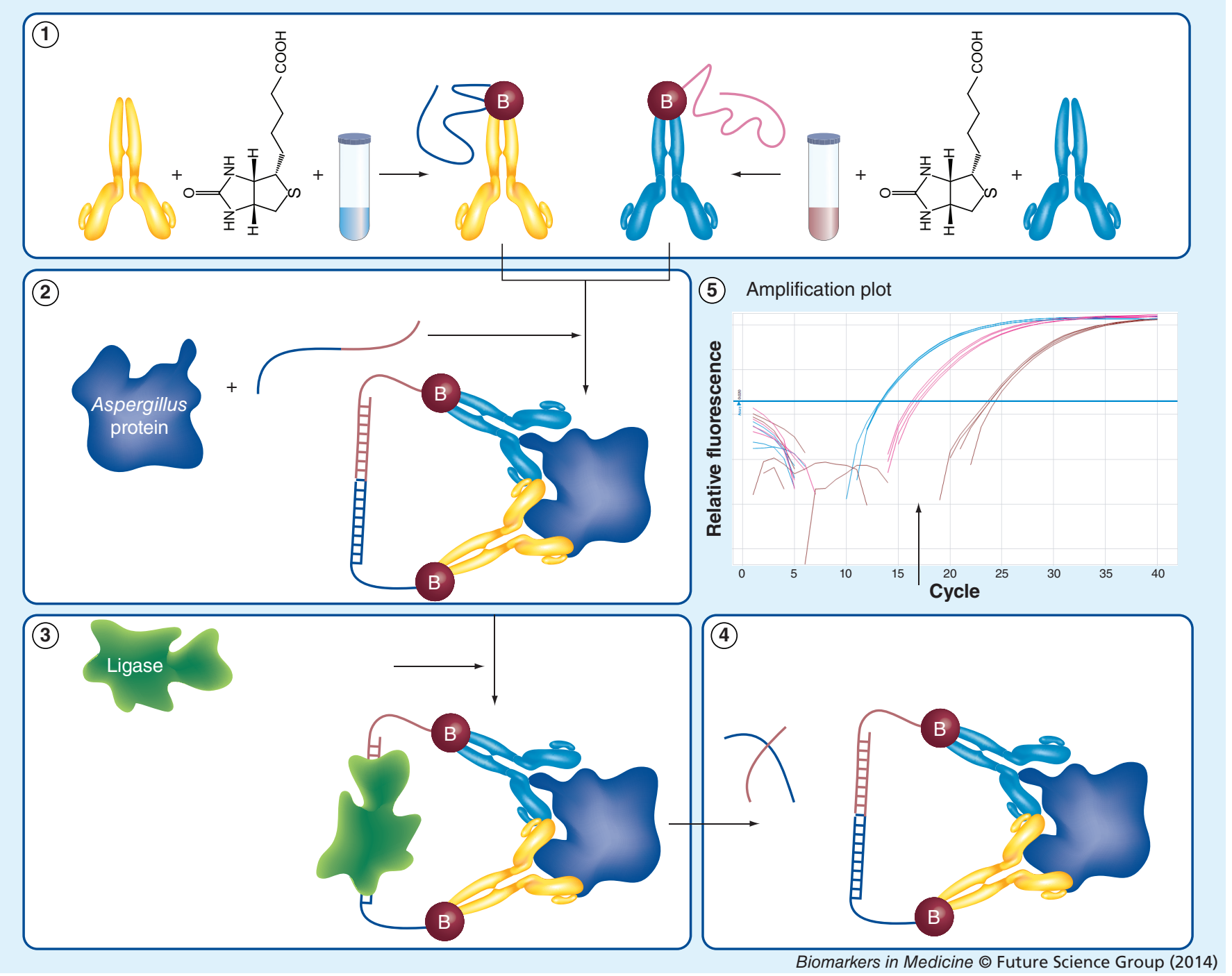

Figure 1. Proximity ligation assay. The proximity ligation assay (PLA) workflow consists of four main steps. (1) Antibodies targeting adjacent epitopes on the same Aspergillus-specific antigen are biotinylated and attached to different streptavidinlinked oligodeoxynucleotides, creating 'proximity probes'. (2) The two probes are combined and incubated with samples, allowing antibodies to bind to their epitopes. The reaction mixture also contains a single-stranded oligonucleotide that is complementary to the ends of the two oligonucleotides. If antigen is present, the oligonucleotides are linked. (3) A ligation reaction seals the gap. (4) This generates a template that can be amplified by PCR. (5) The amplification plot shows a PLA carried out using JF5 antibody. Please see color figure at www.futuremedicine.com/doi/full/10.2217/bmm.13.129

ings can be concentrated by centrifugation and processed with calcofluor white mounts for examination. However, Aspergillus rarely sporulates in vivo, making this approach rather nonspecific [25]. In addition, microscopy offers a low sensitivity $[26,27]$ and structures can only be seen if they are present in abundance, usually at a later stage of infection [28]. Furthermore, morphology-based characteristics are unstable and cannot reliably distinguish between different fungal species [25] (Figure 2). Moreover, clinical Aspergilli sometimes manifest atypically with slow sporulation and aberrant conidiophore formation [21]. Consistent discrimination of these species requires DNA sequence analysis
[29]; hence molecular techniques have been applied to improve the reliability of species identification [30].

Molecular phylogeny groups fungi according to DNA sequence variation in a number of genes ranging from the universal ribosomal DNA regions ITS (Figure 3) and the large ribosomal subunit D1-D2 [31] to protein-encoding genes such as the $\beta$-tubulin and calmodulin gene regions [32]. This has resulted in the identification of new fungal species that are morphologically similar to A. fumigatus, but are genetically distinct [33]. These can be easily misidentified by clinical laboratories, which can have severe consequences as they include human pathogens such as A. lentulus, 
A. viridinutans, N. pseudofischeri and $N$. udagawae [21] that have been reported to be resistant in vitro to antifungal agents such as itraconazole, miconazole, posaconazole, ravuconazole and/or voriconazole [34].

These shortcomings have resulted in a long-term effort to introduce more reliable, robust, reproducible and rapid methods for the diagnosis of IA. The most successful of these have been targeted at Aspergillus antigens or metabolites, with the targeting of DNA hampered by poor assay quality, a lack of standardization and interlaboratory validation and the ever-present risk of contamination [11].

\section{Antibody-targeted biomarkers}

\section{Galactomannan}

GM is a polysaccharide made of a linear mannan backbone with side chains of galactofuran as major carbohydrate constituents. It is present in the cell walls of yeasts and plants as well as a wide variety of fungi, including the genera Aspergillus, Penicillium, Cladosporium and Fusarium [35] and in Aspergillus is synthe- sized in the lumen of the Golgi apparatus [36]. GM is anchored to the membrane via a glycosylphosphatidylinositol or is covalently linked to the cell wall and is readily released as a lipopeptide GM, either in a complex with proteins or as a molecule of about $20 \mathrm{kDa}$ [37]. In vivo the release of GM is believed to occur when nutrients become limited and growth is restricted [38], although in culture GM release peaks during periods of exponential growth [39]. GM release depends on fungal invasion of the endothelium [40], hence detection of circulating GM requires angioinvasion. This is important since not all cases of IA result in angioinvasion: highresolution computed tomography (CT) in neutropenic hematological and stem cell transplant recipient patients reveals angioinvasion as characteristic halos and these patients are almost always positive for serum GM [41]. On the other hand, while a halo sign has been reported in $61 \%$ of patients with invasive pulmonary aspergillosis [42], another report suggests sensitivity can be as low as $25 \%$ and GM positivity in serum is often not accompanied by a CT halo [3]. Angioinvasion is

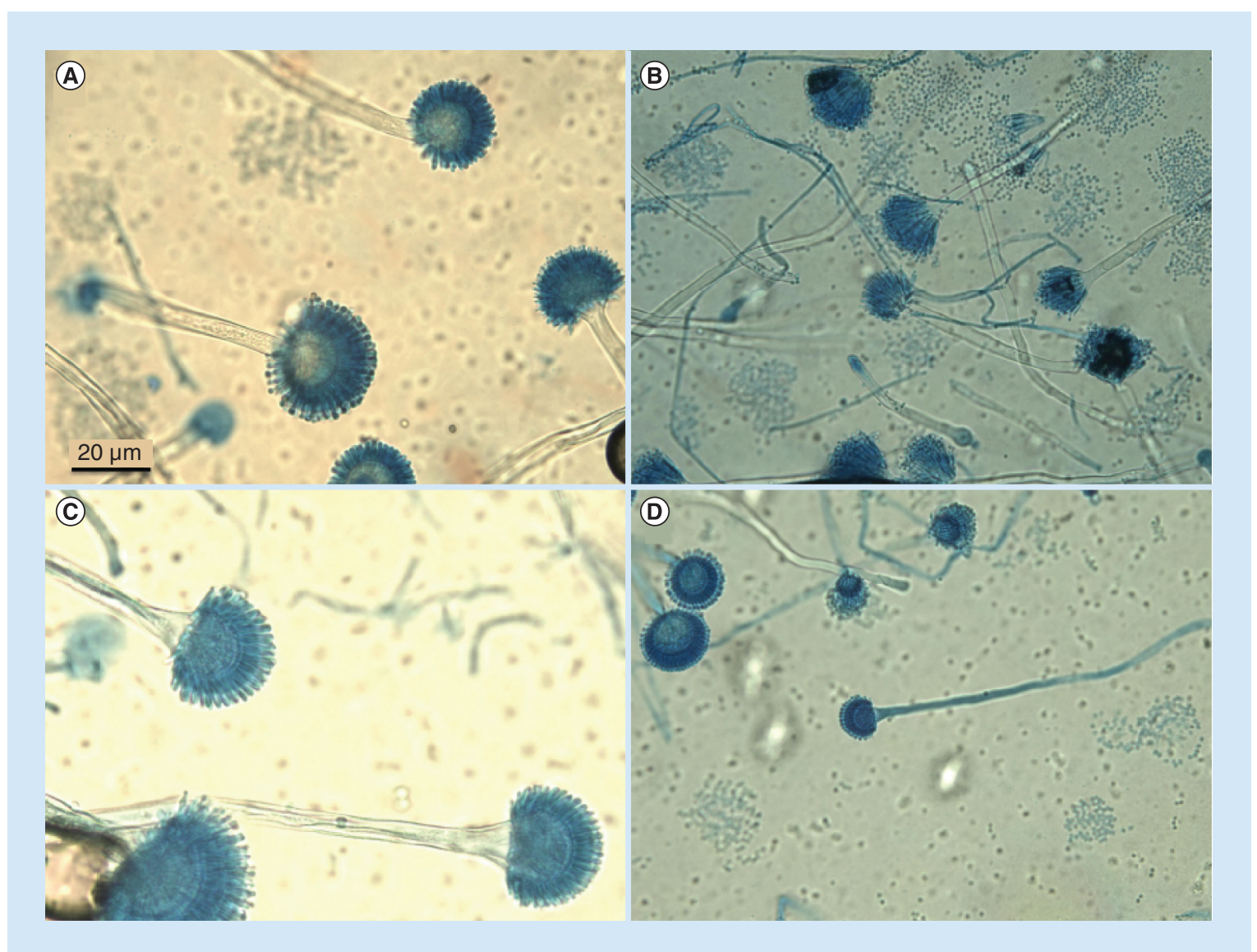

Figure 2. Microscopic views of different fungi reveal the similarities between different Aspergillus species.

(A) Aspergillus niger, (B) A. candidus, (C) A. flavus, (D) A. fumigatus.

Reprinted with permission from Melvyn Eydmann and Tim Linehan (Microbiology Department, Royal London Hospital, UK).

Please see color figure at www.futuremedicine.com/doi/full/10.2217/bmm.13.129 


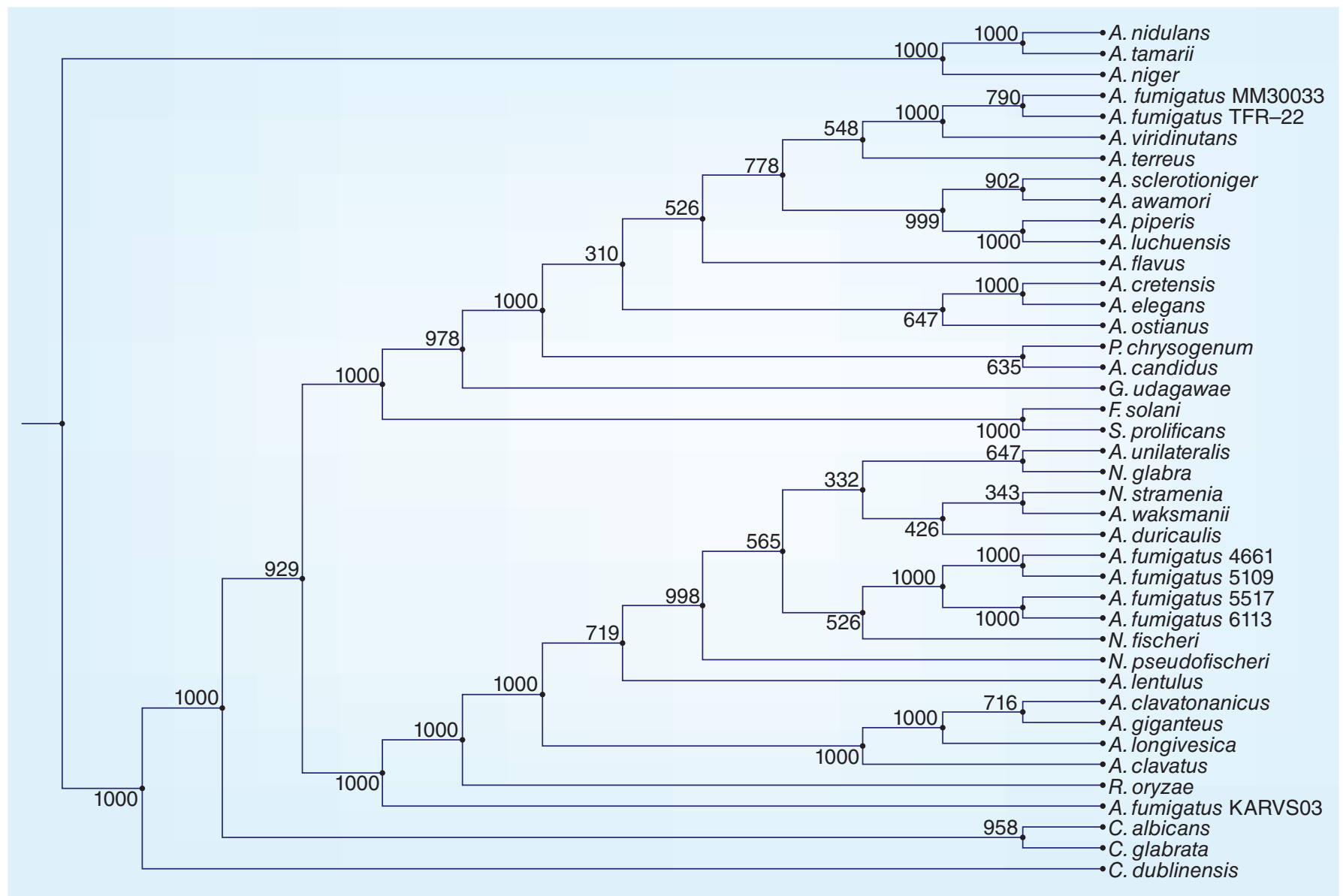

Figure 3. Phylogenetic tree based on fungal 185 ribosomal DNA sequences using the unweighted pair group method with arithmetic mean algorithm from the CLC Sequence Viewer 6.8.2 (CLC bio A/S, Denmark). Several Aspergillus fumigatus strains cluster together at different locations, all Candida cluster together and Penicillium chrysogenum is closely related to $A$. candidus. The branch annotations are the bootstrap values obtained from 1000 bootstrap tests.

Please see color figure at www.futuremedicine.com/doi/full/10.2217/bmm.13.129

also less common in patients with chronic granulomatosis, characterized by lung abscess development, and these patients are often GM-negative [43].

A double-sandwich ELISA, the Platelia ${ }^{\mathrm{TM}}$ Aspergillus enzyme immunoassay (Bio-Rad, France), has been developed that uses the EBA2 monoclonal antibody both as detector and acceptor for GM [44]. The US FDA approved this assay in 2003 as an adjunctive test for IA diagnosis when applied to serum; a positive serum GM result is also included in the microbiological criteria of the revised EORTC/MSG classification of IA [6]. Test results are interpreted as a GM optical density (OD) index (GMI), which is the ratio of the sample OD divided by the mean OD of two threshold controls (Figure 4A). The FDA has cleared a GMI cutoff of 0.5 , as this allows sensitive detection with minimal loss of specificity and recommends that positivity should be confirmed by repeating the test on the same specimen. The test can detect as little as $0.5 \mu \mathrm{g} / \mathrm{ml}$ of GM and a positive result can be obtained in $65 \%$ of patients around 5-8 days before clinical signs of IA develop, in $71 \%$ before findings on chest $\mathrm{x}$-ray become apparent and in $100 \%$ of patients before cultures yield a positive result [45].

Nevertheless, there are some doubts about the clinical utility of recording a serum-positive GM result in the nonculture-based diagnosis of IA. Although early reports indicate both high sensitivity and specificity, more recent studies have found a lower sensitivity, ranging from 40 to $50 \%$, particularly in the setting of mould-active antifungal agents and with nonserial testing [46]. Another report concludes that while GMbased diagnosis is associated with high specificity, it appears to be better for detecting non- $A$. fumigatus Aspergillus species [47]. Other studies challenge the specificity of the GM ELISA: it detects a soluble antigen produced during infection with Geotrichum capitatum, with no evidence of aspergillosis [48], crossreacts with other opportunistic fungi in some other fungal infections such as histoplasmosis [49] and may 
react with antigens from Cryptococcus neoformans in patients with cryptococcosis [50]. Early problems with false-positive results from patients receiving $\beta$-lactam antibiotics [51] may have been caused by the presence of cross-reacting antigens from Penicillium during manufacturing [52], and are largely resolved [53]. Certainly the clinical problem can be minimized if batches are tested before use and/or if samples are collected prior to administration [54].

There have been several studies that set out to investigate the clinical validity of serum GM testing for the diagnosis of IA. The first systematic review of 27 studies of serum GM testing for the diagnosis of IA in immunocompromised patients published between 1996 and 2005 concluded that the assay has moderate accuracy, observing significant heterogeneity between the studies, dependent on patient population and type of reference standard used, with a lack of sensitivity in patients with solid organ transplantation [55]. This heterogeneity was also apparent in a second [56] and third meta-analysis [57], although in the first two only a minority of studies used the 0.5 GMI cut-off that is the current standard. There are several reasons for the observed variability in sensitivity of the serum GM assay. These include the effects of antifungal prophylaxis, where the sensitivity is 52\% compared with $89 \%$ in patients not receiving therapy [58], the level and nature of immune suppression of the patient [59], but also technical parameters such as frequency of testing, whether IA is defined by one or two positive sera or what cut-off is used [25].

Another reason for the high degree of variability is the lack of reproducibility observed with repeat testing of the same serum samples, especially when testing samples with a GMI from 0.5-0.7 [60]. Lower reactivity on retesting has also been reported in $20 \%$ of samples stored for 4 years [61], another study found a lack of reproducibility when GM-positive samples were retested within 6 days [62], a third study reported a similar reduction in reactivity of samples on retesting of positive samples within 3 days [63] and a fourth study confirmed the reduction in GM signals in serum samples, but not in BAL fluids [64]. These reports emphasize the importance of corroborating a positive result by retesting of the same sample and also raise doubts about the interpretation of data from frozen/ thawed samples, as well as samples tested in 'real-time' for patient management.

In addition to serum, GM testing has also been applied to other body fluids [65]. BAL fluid has been investigated thoroughly, since it was reported that detection of GM in BAL fluid increased the diagnostic sensitivity from $47 \%$ in serum to $85 \%$ [66], a comparison of 33 cases found that all $33 \mathrm{BAL}$ specimens, but only nine serum specimens, were positive [67] and that BAL fluid from an established guinea pig model of IA gave a positive result more than 2 days sooner with BAL fluid than with serum [68]. This approach has been investigated for early diagnosis of IA following hematopoietic stem cell transplants [69], after solid organ transplantation [70], in patients with hematological malignancies and pulmonary infiltrates [71], chronic pulmonary disease [72-74] as well as in intensive care units [75] and in nonimmunocompromised patients [76]. Nevertheless, its impact on clinical outcome is uncertain: our analysis of the assay sensitivity reported in these studies shows variation from 57 to $88 \%$, with the specificity ranging from 87 to $95.8 \%$, and positive-predictive values in the range of 41.7 to $92.5 \%$, when using a GMI cut-off of 0.5 . Furthermore,

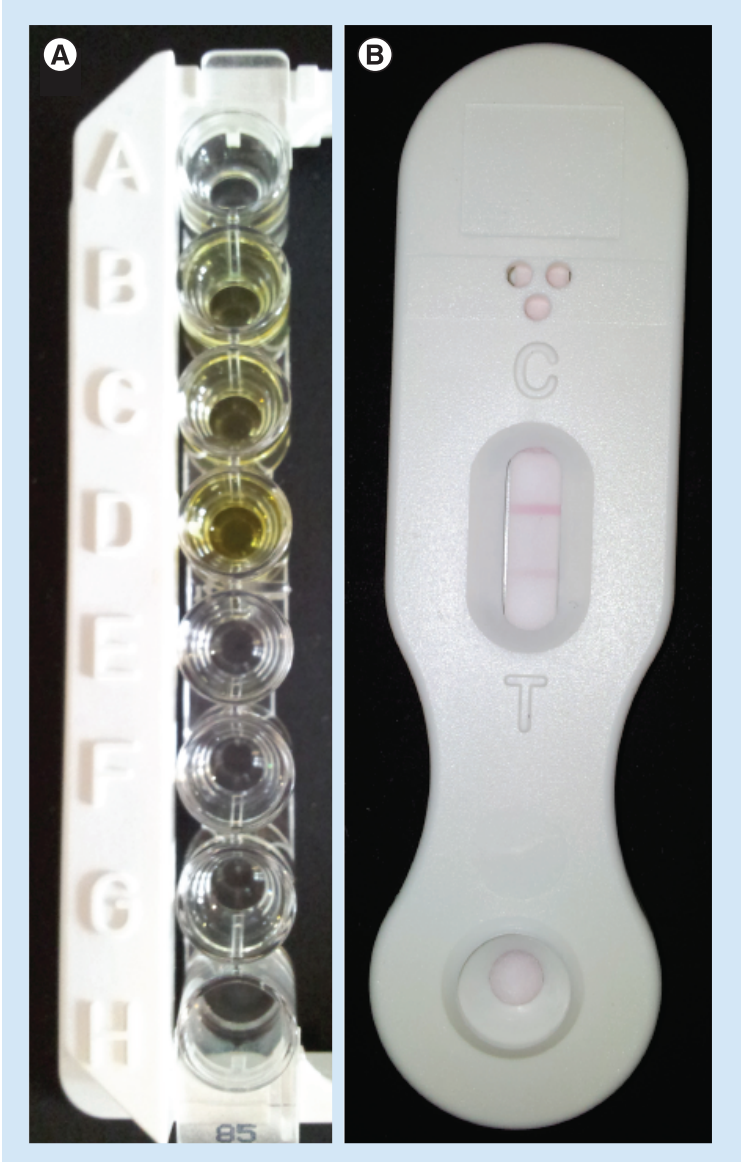

Figure 4. Antibody-based detection of Aspergillus antigens. (A) Colorimetric detection of GM. Key: clear: GM absent; yellow: GM present. (B) Lateral flow device showing a positive result for Aspergillus detection, indicated by the two bands, one of which serves as a positive assay control and the other being specific for the presence of antigen recognized by the monoclonal antibody JF5.

Please see color figure at www.futuremedicine.com/ doi/full/10.2217/bmm.13.129 
the background level of GM is greater in BAL fluid than in serum [25], which has led to considerable discussion, but no agreement, about the most appropriate diagnostic cut-off. There is one report suggesting a cut-off of 0.2 [77], but given the high levels of GM this is likely to lead to a large number of false positives. Individual studies suggest cut-offs of 0.5 [78,79], 0.8 [80], $0.87[81], 1.0[82,83], 1.1[84], 1.5$ [85] or 2.0 [86] to avoid over-diagnosis. A recent systematic review and metaanalysis of detecting GM in BAL for diagnosing IA suggests an optimal cut-off of 1.0 [87].

Not surprisingly, the sensitivity of GM detection in BAL has been questioned [88] and problems with falsepositive results have also been reported [75], most obviously with the use of fluids that contain GM, such as plasmalyte [89] but also in patients receiving $\beta$-lactam antibiotics at the time of bronchoscopy [77,90], although the latter issue appears to have been resolved. In addition, there is an urgent need to establish a standardized method of BAL collection, since the means and volume of collection, dwell time of instillate before aspiration, number of washes and sample handling vary widely and affect assay performance [88].

Urine has several advantages over serum or BAL fluids: it permits diagnosis without invasive tissue sampling, so reducing the likelihood of complications and resulting morbidity; is more convenient to use as it requires no sophisticated laboratory processing; and it is ideal for use with lateral flow diagnostic tests for use at point-of-care. The feasibility of this approach has been demonstrated in a recent report that used a novel IgM monoclonal antibody (mAb476) that recognizes GM-like antigens from Aspergillus and other molds, together with a lateral flow immunochromatographic assay to detect urinary excreted antigen in IA patient urine samples [92]. However, it remains to be seen whether the time course of GM expression is compatible with early diagnosis and if standardized pretreatment is critical.

\section{$1,3 \beta$-D-glucan}

$1,3 \beta$-D-glucans (BDGs) form a major heterogeneous polysaccharide component of the cell wall of most pathogenic fungi, with some exceptions such as Cryptococcus neoformans and Zygomycetes [93]. BDG was isolated and characterized by the same group that identified GM as the circulating antigen in patients with IA, but was found to be nonantigenic [94]. Instead, assays make use of the ability of BDG to activate a cascading series of serine proteases in the Limulus amoebocyte lysate coagulation cascade. The presence of BDG is detected either by a turbidimetric assay or via cleavage of a synthetic chromogenic substrate. BDG has been included in the revised EORTC/MSG diagnostic definitions for invasive fungal diseases on the basis of promising early results from a multicenter validation study [95], although it is unable to distinguish among fungal etiological agents. Its utility as an adjunct in the diagnosis and management of IA is suggested by recent data that showed a sensitivity and specificity of 63 and $93 \%$, respectively, in patients with acute leukemia using two consecutive samples with a cut-off value of $7 \mathrm{pg} / \mathrm{ml}$ [96]. The test gave similar results for IA and candidiasis, although the time interval between onset of fever and BDG result was shorter for IA. Positive BDG test results were obtained before the results of any other conventional diagnostic method, including cultures, histopathology or radiological criteria, which may make it useful for early evaluation and preemptive initiation of appropriate antifungal treatment. A recent meta-analysis of 16 studies concluded that serum BDG measurement has a good diagnostic accuracy for IFD diagnosed in accordance with the EORTC/MSG criteria, with a pooled sensitivity of $76.8 \%$ and a specificity of $85.3 \%$ [97]. However, as with the GM studies, there was marked statistical heterogeneity among the studies [25]. With regards to the clinical utility of the BDG assay, there were significant technical differences between the studies, extending to the method of measurement, the type of $\beta$-glucan used as standard, the pretreatment method and the cut-off levels [97]. Similar results were reported by another meta-analysis that included 17 studies where IA was specifically targeted as a subgroup for analysis; here sensitivity and specificity were 77 and $83 \%$, respectively, and heterogeneity was equally significant [98]. In addition, the timing and frequency of BDG testing for patients at risk has not been standardized, and neither have the criteria for defining a positive test result. A study focusing on routine use of BDG for panfungal screening of IFD in patients with hematological malignancy revealed limited usefulness of this test in such setting, with low sensitivity combined with an extremely low positive-predictive value (11.8\%) being the major limitations [99]. There are also factors other than a fungal infection that could generate positive BDG results, for example, the cellulose membranes used for hemodialysis contains BDG and BDG can be introduced into blood by medical intervention [93]. Hence this assay shows promise, possibly in combination with GM testing, but clinicians need to be aware of its operating characteristics, sensitivity and potential to generate false positive results in order to apply them in the appropriate setting [100].

\section{Other biomarkers}

Aspergillus spp. produces a range of extracellular enzymes as well as primary and secondary metabolites that promise additional specificity unimpeded by the 
presence of cross-reactive epitopes in patient specimens and that could serve as better surrogate markers of infection. For example, immunodetection of human $\mathrm{IgG}$ directed against the Aspergillus gliotoxin oxidoreductase [101] may have potential as a diagnostic biomarker of IA in nonimmunocompromised individuals [102].

A new ELISA has been described that is based on two monoclonal antibodies that recognize epitopes present on the cell walls of the hypha and conidia of Aspergillus. These circulate or are excreted as immunodominant antigens during the acute phase of IA in rabbit models of the disease and its sensitivity is comparable to that of the Platelia ELISA kit, with a specificity of $100 \%$ when tested against both serum and urine samples [103]. There was no cross-reactivity with purified GM antigen from Aspergillus or with common opportunistic fungi such as $P$. marneffei and Candida albicans, C. glabrata, C. tropicalis, C. krusei and C. parapsilosis, although no other fungal species were tested.

A second study describes the generation of the Aspergillus-specific monoclonal antibody JF5, which binds to an extracellular glycoprotein antigen that is secreted during active growth of the fungus only [14]. JF5 was used to develop an immunochromatographic LFD for the detection of Aspergillus antigen in human serum and BAL fluids (Figure 4B) and its utility for diagnosis of IA was demonstrated using an animal model of infection, where it had superior sensitivity, specificity and speed compared with GM and BDG assays [104]. The LFD assay is reproducible between different laboratories and studies [105] and its speed and accuracy provide a novel adjunct point-of-care test for diagnosis of IA in hematological malignancy patients [106].

A number of other targets for the detection of A. fumigatus by ELISA have been described. These include the surface protein $\mathrm{Cf} 2$, which was isolated from a human patient with proven IA and is also present in growing hypha of $A$. fumigatus but not in spores [107] as is Asp f6/MnSOD [108], gliotoxin, which is produced by most $A$. fumigatus strains and is present in plasma and serum [109] and its inactive derivative bis(methylthio)gliotoxin, which is also recoverable from blood [110], 15 immunogenic proteins of the immunosecretome [111] and secreted proteases whose activity in serum specimens might serve as a new diagnostic approach if used with reporter peptides [112].

Iron, an indispensable cofactor for many cellular processes including electron transport, amino acid metabolism and biosynthesis of DNA, is a key nutrient for most organisms, including Aspergillus [113]. However, since iron excess or incorrect storage can catalyze the formation of reactive oxygen species, Aspergillus has evolved complex mechanisms to balance its acquisition, storage and consumption [113]. Under iron-limited conditions one strategy involves the biosynthesis of siderophores, which are low molecular mass iron chelators that acquire iron from the environment [114] (Figure 5). Fusarinine $\mathrm{C}(\mathrm{FsC})$ and triacetylfusarinine $\mathrm{C}$ (TAFC), the major siderophores produced by $A$. fumigatus to mobilize extracellular iron are produced within hours of spore germination and, along with the intracellular siderophore ferricrocin, are essential for its virulence [115]. In a rat infection model, radiolabelled TAFC shows highly selective accumulation in infected lung tissue and good correlation with severity of disease, strongly suggesting that it is a promising agent for $A$. fumigatus infection imaging [10]. Furthermore, since the fungus secretes large amounts of FsC and TAFC early in its life cycle, diagnostic tests have been developed to detect these analytes in serum and urine as biomarkers of infection [116]. Indeed, $\mathrm{Fs}$ C has been specifically detected in serum and urine obtained from $A$. fumigatus-infected immunocompromised guinea pigs, but not in uninfected animals [116]. However, investigations on clinical samples remain to be carried out.

\section{Breath tests}

Collection of exhaled breath condensate (EBC) is a convenient and noninvasive method for obtaining aerosolised sample molecules from the lungs (Figure 6). It can be used for repeated sampling, even in mechanically ventilated patients and can be collected from young babies to the elderly with no need for active cooperation from the patient. EBC contains a large number of volatile (VOC) and nonvolatile organic compounds such as isoprostanes, leukotrienes, nitrogen oxides, peptides and cytokines [117], whose concentrations are influenced by inflammation, lung diseases or the presence of pathogens and modulated by therapeutic interventions [118].

VOCs, of which there are more than 500 in breath, are promising targets for diagnostic testing, especially if the biochemical pathways by which they are produced can be linked to specific pathogens [119]. 2-pentylfuran is a VOC that falls into this category: it is produced by $A$. fumigatus, but not by mammalian metabolism. It could not be detected in breath samples from normal controls analyzed by gas chromatography/mass spectrometry but was present in the breath of at-risk patients infected with $A$. fumigatus [120]. However, a recent review concludes that careful attention needs to be paid to the sensitivity and specificity of VOC testing as contamination from the environment has a confounding effect and that, overall, EBC is disappointing as a diagnostic sample [121].

Many investigators have reported the detection of genomic [122], mitochondrial [123] and viral [124] 


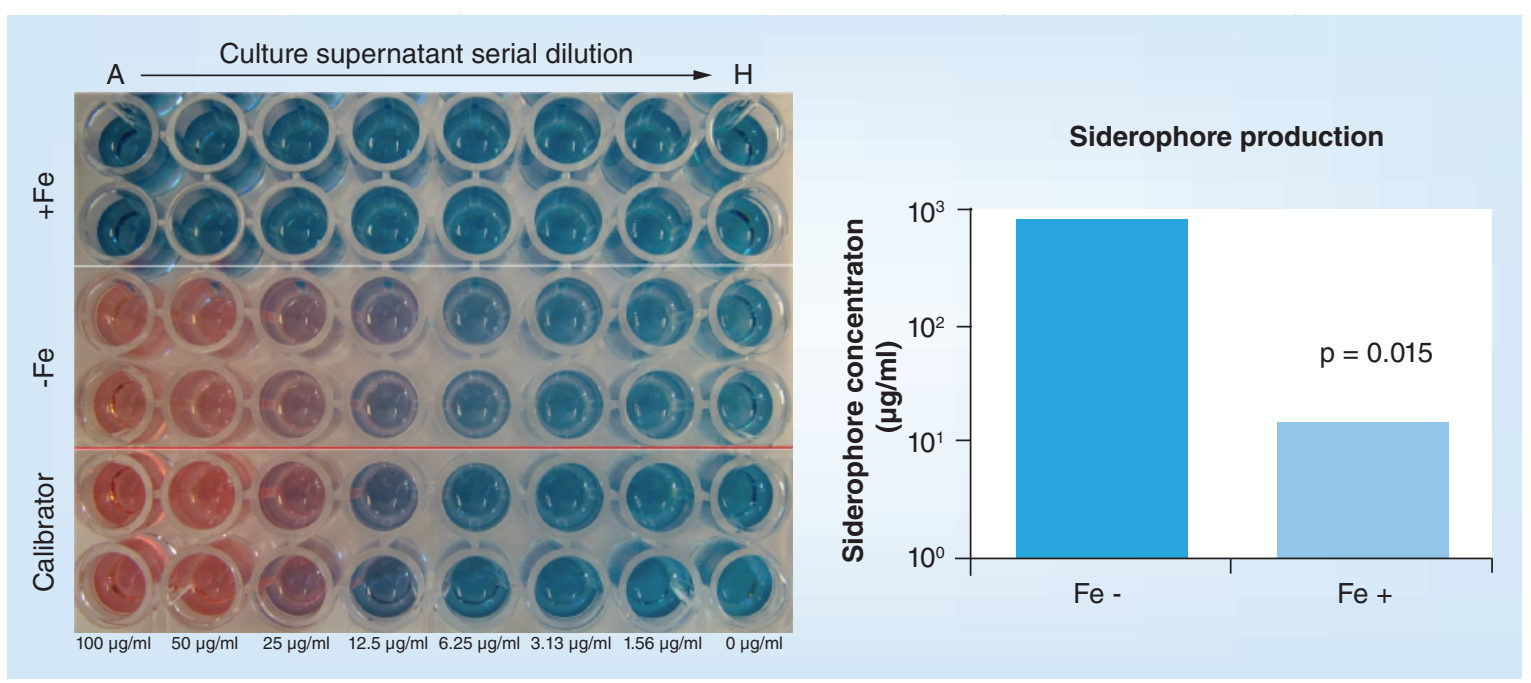

Figure 5. Colorimetric detection of siderophore production by Aspergillus fumigatus under iron-free and replete conditions, respectively. Maximum siderophore production $(800 \mu \mathrm{g} / \mathrm{ml})$ was evident when Aspergillus fumigatus was cultured in the absence of iron. Key: blue: siderophores absent; orange/pink: siderophores present. Please see color figure at www.futuremedicine.com/doi/full/10.2217/bmm.13.129

DNA in exhaled breath and have subjected EBC to detailed molecular and microscopic analysis of bacteria and viruses [125]. However, a comparison of assays based on the detection of microbial nucleic acids from $\mathrm{EBC}$ and from spontaneous sputum in patients with acute exacerbations of chronic obstructive pulmonary disease found that the results did not correlate well [126]. Another study was unable to detect the IS6110 repetitive DNA element of Mycobacterium tuberculosis in EBC of patients with newly diagnosed active pulmonary TB [127]. Other studies looking at the potential utility of detecting RNA [128] or DNA [129] from viral pathogens concluded that EBC is unsuitable for clinically relevant detection of viral nucleic acid in the respiratory tract of lung transplant recipients, although changes to sampling techniques [130] or appropriate fractionation [131] of EBCs may lead to improved results. Hence a more optimistic interpretation of these results is that the translation of the obvious potential of EBC into a practical diagnostic utility will require understanding of the technical problems and subsequent careful optimization of the many steps involved from sample collection to target analysis.

There are no reports in the peer-reviewed literature of EBC screening with GM. A preliminary report suggests it may be more sensitive than serum testing and that EBC-positivity may predate GM detection in BAL fluid or abnormal high-resolution CT signs [132]. Another early report evaluated the role of GM testing in EBC for early diagnosis of IA in severe chronic obstructive pulmonary disease and confirmed that positivity in EBC may precede that of serum but found the sensitivity to be lower compared with serum [133].
Both studies were carried out on low patient numbers and have not yet been followed up with peer-reviewed publications.

\section{Nucleic acid detection methods}

Nucleic acid-based tests (NATs) comprise a range of amplification technologies and sophisticated detection methods that are readily adaptable for use in the fungal diagnostic laboratory [134] The most commonly used NAT is real-time qPCR, although there are a few reports describing the use of nucleic acid sequencebased amplification, an isothermal technique for the amplification of RNA that is especially powerful when combined with molecular beacon chemistry [135-138]. However, the theoretical advantage of higher sensitivity and reduced likelihood of carry-over contamination must be balanced by the complexity of this technology: it requires a combination of three enzymes, the avian myeloblastosis virus, reverse transcriptase/ DNA polymerase, T7 RNA polymerase and a separate RNase H [134]. Similarly, while another NAT, microarray technology, has the potential to concurrently detect many target nucleic acids from multiple organisms for simultaneous species identification [139], detection of virulence factors and antifungal resistance determinants [140] as well as gene expression profiling in the context of IFI [141], its practical adoption is hindered by its low dynamic range and variable hybridization efficiencies, resulting in unreliable quantification and false-positive/negative results [142]. Unfortunately, these problems are inherent to microarray technology; practical applications of microarray technology as clinical diagnostic assays require the introduction of new detection chemistries and analysis approaches [134]. 


\section{$P C R$ \& IA}

Owing to the potential of noninvasive serial sampling for monitoring, blood has long been a focus for the detection of Aspergillus DNA, making PCR a potential diagnostic method of choice. The presence of viable fungi is rather rare, as evidenced by poor blood culture results, although this may have been due to collection and subculture procedures [143]. The European Aspergillus PCR Initiative (EAPCRI) have published protocols for DNA extraction from serum [144] and whole blood [145], although these protocols were developed and validated using blood spiked with Aspergillus conidia. These methods require extensive and harsh extraction methods that can damage DNA and RNA to the extent that amplification becomes unreliable [11]. Interestingly, such harsh extraction steps may not be required since Aspergillus present in blood is highly unlikely to be conidial as Aspergillus rarely sporulates in vivo [25].

Marker detection in blood, serum and BAL fluid has been investigated in a guinea pig model of IA [146]. The authors found BAL fluid to be the most suitable sample for early diagnosis of IA by day 3 (postconidia inhalation) using PCR, GM and BDG assays. Marker levels remained elevated throughout the study. Despite high fungal burden within tissue and BAL samples, it was found that serum and whole blood can remain negative with all three assays, even at an advanced stage of disease. This study, however, did not include any antifungal treatment, which can result in a significant reduction of serum marker levels, whereas marker levels may remain elevated in BAL fluid [105]. The usefulness of BAL fluid is underlined by the finding that a combination of PCR, PCR-ELISA and GM testing in the BAL fluid of patients with hematological malignancies was shown to enhance routine laboratory diagnosis of IA [147].

Both conventional, gel-based endpoint PCR and real-time qPCR methods have been used for the detection of Aspergillus. However, qPCR has several key advantages for clinical testing [148]:

- Simplicity: qPCR follows a basic, three-step workflow: nucleic acid is made accessible from a biological sample; a specific nucleic acid is amplified using pathogen-specific DNA oligonucleotide primers; and amplification products are detected either in real-time or at the end of the assay;

- Sensitivity and specificity: qPCR has a theoretical detection limit of fewer than five copies of nucleic acid target, coupled to a capability for specific differentiation of closely related species or subtypes as well as characterization of sequence variation. Fungal nucleic acid provides the ultimate biomarker for IA, as a carefully chosen target sequence will result in the exclusive identification of the pathogen involved;

- Speed: a qPCR assay can be completed and results analyzed in minutes;

- Minimal contamination risk: since there is no post-PCR handling of amplification products, the risk of contamination is significantly reduced compared with the need to pipette potentially high copy numbers of Aspergillus DNA and run them on gels.

In addition, there are other advantages that include convenience, robustness, potential for high throughput and quantification, familiarity with its advantages and disadvantages and relatively low cost [149] (Figure 7).

As with legacy PCR, there are several drawbacks to qPCR:

- A qPCR assay can only be designed if there is prior target sequence information;

- The need to use purified nucleic acids limits the practicality of qPCR in a clinical setting, since it increases the time needed for sample preparation and increases the likelihood of contamination [25];

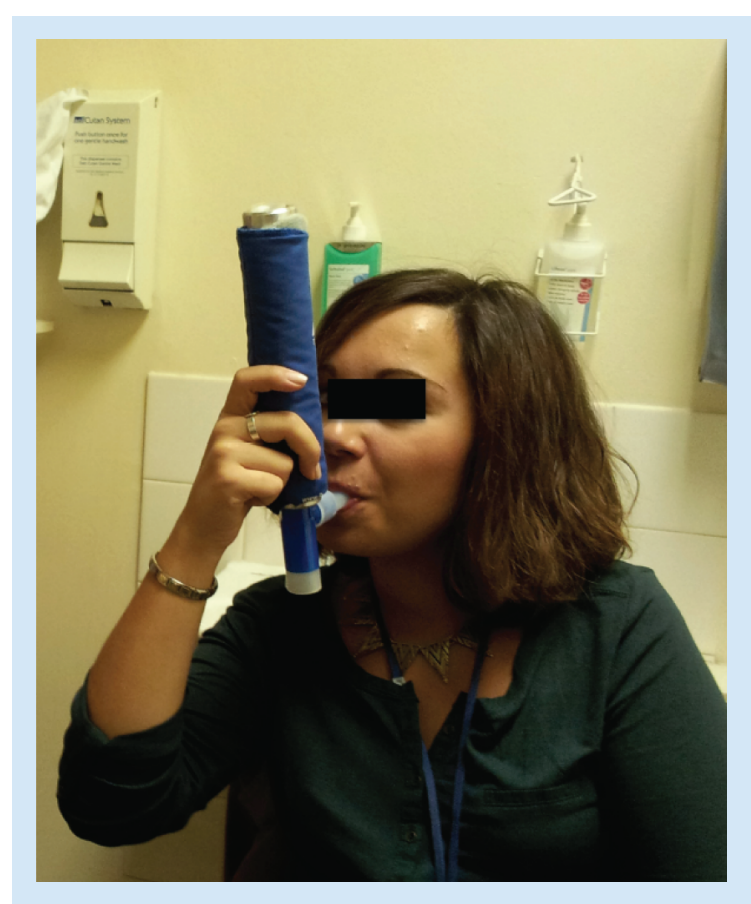

Figure 6. Collection of exhaled breath condensate using a condensation device designed to exclude gross salivary contamination. Patients sitting comfortably breathe at tidal volumes into a mouthpiece attached to a cold condenser for approximately $10 \mathrm{~min}$.

Please see color figure at www.futuremedicine.com/ doi/full/10.2217/bmm.13.129 
- $\mathrm{qPCR}$ is sensitive to environmental inhibitors that are concentrated along with pathogens during sample processing;

- The small volumes assayed [150] or some of the reagents used [151] may lead to false-negative results because of low fungal loads;

- Perhaps most crucially, assays determine only pathogen number and provide no information on whether a pathogen can establish an infection. Hence a positive result may not necessarily pose a public health threat. However, a combination of selective DNA extraction and intelligent targeting of the qPCR assay may allow qPCR assays to distinguish between germinated and nongerminated conidia [152].

As a consequence, the clinical utility of this approach remains limited despite the development of numerous qPCR-based assays claiming early as well as reliable diagnosis of IA [153].

Crucially, there are no externally validated methods for PCR-based diagnosis, and there is a lack of standardization of protocols, with qPCR assays using disparate chemistries, different targets, there is sample-specific instrument-dependent variability and some assays use contamination-prone nested PCR methods aimed at enhancing analytical sensitivity [154]. This inconsistency is further highlighted by a recent meta-analysis of 16 PCR studies applied to whole blood, serum and plasma, which included three extraction and four disruption methods, three different starting volumes, three different specimen types, three different target genes and four different PCR methods [155].

The same meta-analysis showed an overall sensitivity of $75 \%$ and specificity of $87 \%$ when two positive samples were used; a single sample gave an increased sensitivity of $88 \%$ at the cost of a reduced specificity of $75 \%$. This is rather similar to the results of a second meta-analysis that analyzed studies published between 1993 and 2012 and recorded an overall sensitivity of $77.2 \%$ and a specificity of $93.5 \%$ [156]. This poor performance and variability is a general characteristic of other PCR assays aimed at diagnosing IA, with one study reporting a complete lack of sensitivity [157], another $33-100 \%$, depending on DNA extraction procedure [158] and others anything around $50-58 \%$ [159], 64\% (BAL) or 73\% (serum) [147], 75\% [160], 80\% [161,162] or $91 \%[163]$.

There is also heterogeneity in the results of studies that compare the diagnostic performance of PCR to that of GM in BAL: one suggests that they are similar, with PCR being slightly more sensitive [156], another that GM is more sensitive and more specific [79]. Nevertheless, both conclude that positivity for both GM and Aspergillus PCR in BAL is highly suggestive of a pulmonary aspergillosis and that performing both tests results in optimal sensitivity with no loss of specificity $[79,156]$.

This lack of concordance between PCR-based data is not limited to assays targeting Aspergillus: a survey of the general qPCR-based literature identified significant shortcomings with both the transparency of reporting and the quality of qPCR assays [164], a problem confirmed by a second, large-scale study [194] [Bustin ET AL., Submitted Manuscript]. This inconsistency and lack of reproducibility underlies the decision of the EORTC and MSG of National Institute of Allergy and Infectious Diseases not to endorse the routine use of PCR in the diagnosis of IA. There have been two developments that may improve the reliability of PCR-based assays for the diagnosis of IA. The first one could have a direct effect and involves the EAPCRI, which was formed with the aim of providing optimal standardized protocols for diagnostic Aspergillus PCR from serum. In a series of publications, its members have:

- Asserted that the efficiency of Aspergillus PCR is limited by the DNA extraction procedure and not by PCR amplification [165];

- Proposed guidelines for optimal DNA extraction [145];

- Concluded that the testing of serum by Aspergillus PCR can be performed using commercial nucleic acid extraction methods, providing standardization and quality control [144].

Although this initiative is laudable, there is a problem with their interpretation of their own data. We have analyzed the data shown in that publication's Table 2 [165] and discovered that the amplification results obtained using the range of assays tested are highly variable. Excluding one assay that gives no result at all, the detection threshold in different centers ranges from 0.27 to 270 copies of target $/ \mathrm{ml}$, a considerable 1,000 fold difference that can easily account for the difference between a positive and a false-negative result. Our analysis demonstrates that there is a maximum difference of 100-fold when the same PCR strategy is carried out in different centers, readily explaining the variability commented on by the authors of the meta-analyses [149]. Consequently, far from leading to the conclusion made by the EAPCRI, the appropriate conclusion is that the PCR assays are highly variable, with different PCR efficiencies resulting in significantly different sensitivities. 

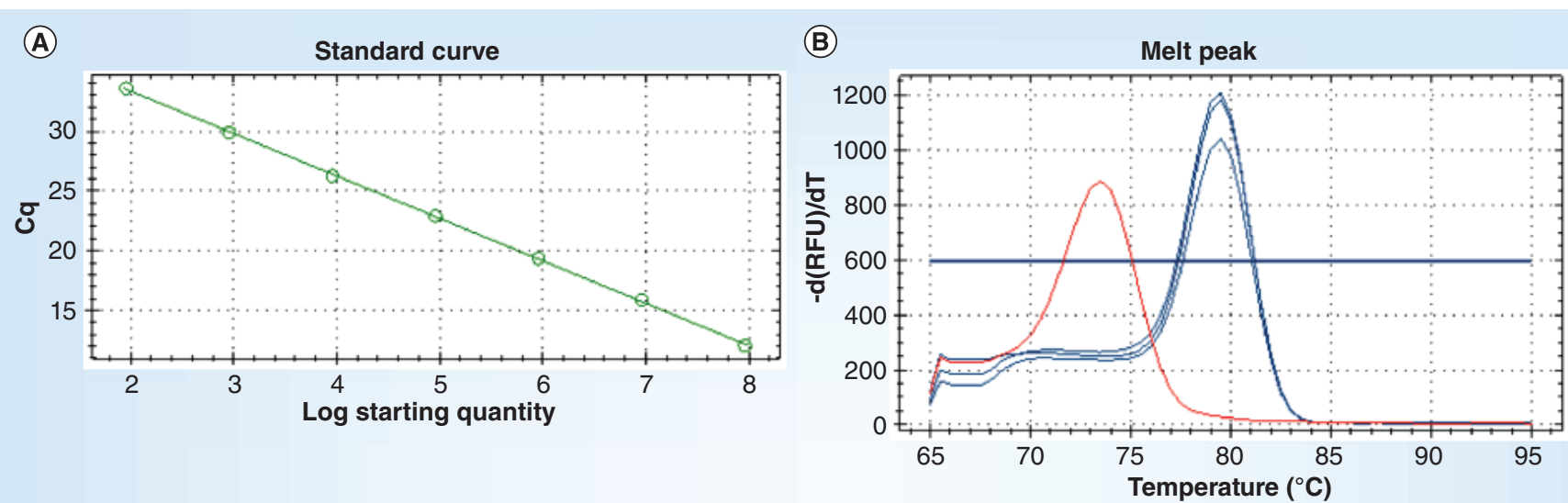

(C)

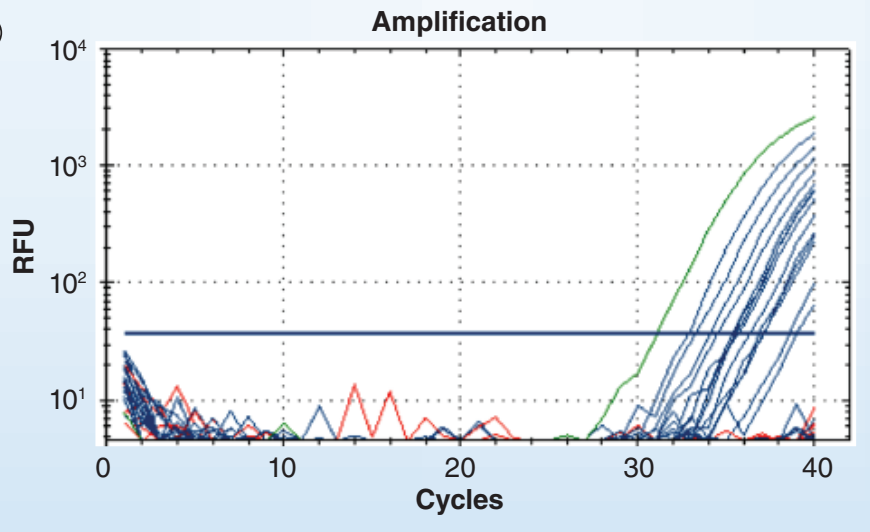

Figure 7. Real-time quantitative PCR data illustrating quantification of fungal load. (A) Standard curve showing the dynamic range of a typical real-time quantitative PCR assay and its efficiency (here $91 \%$ ). (B) Melt curve demonstrating the presence of a single Aspergillus terreus amplicon (blue) at around $80^{\circ} \mathrm{C}$, with a negative control showing a different melt curve indicative of primer dimers at around $73^{\circ} \mathrm{C}$. (C) Typical amplification plots of an Aspergillus fumigatus 28S-specific assay obtained from DNA extracted from bronchoalveolar lavages showing the presence of Aspergillus DNA (blue plots). The green plot is the positive control, all no template controls (red) are negative.

Please see color figure at www.futuremedicine.com/doi/full/10.2217/bmm.13.129

This is where the second development comes in: it is aimed at improving the standard of qPCR assays in general, but with obvious implications for assays aimed at diagnosing IA and concerns the publication of guidelines recording the 'minimum information for the publication of real-time qPCR experiments' (MIQE) [166]. These provide a blueprint for good assay design and aim to restructure today's free-for-all qPCR methods into a more consistent format that will encourage detailed auditing of experimental detail, data analysis and reporting principles [167]. MIQE has become acknowledged as the defining event in the maturing of qPCR technology and its implementation is essential if qPCR is to remain the benchmark technology for molecular diagnosis [11]. The first qPCR assay targeting Aspergillus species designed, optimized and validated in strict compliance with the MIQE guidelines has been published recently [149]. The authors of that publication also analyzed the quality of some of the previously published qPCR assays and suggest that many Aspergillus $\mathrm{qPCR}$ assays use primers designed for conventional PCR assays, which can lead to suboptimal qPCR as in one study that quotes a PCR efficiency of $77 \%$. In addition, a significant number of studies fail to use or report the use of negative extraction controls to monitor contamination during the extraction stage and even though it is well known that PCR inhibitors can reduce product yield and even result in complete failure of the PCR, only just over half of the studies evaluated using the MIQE guidelines reported the use of some form of an inhibition or amplification control [153].

\section{Mass spectrometry}

MALDI-TOF MS separates molecules based on differences in mass:charge ratio and combines the parallel testing capability offered by microarrays with the accuracy of nucleic acid sequencing [168]. It represents a fresh approach that has the potential to replace conventional fungal identification techniques for a majority of routine isolates encountered in clinical microbiology laboratories [169]. Biomolecules such as nucleic 
acids, metabolites, proteins or whole microorganisms are embedded in a crystalline matrix of $\alpha$-cyano- 4 hydroxy-cinnamic acid, vaporized and ionized in a vacuum by a short laser pulse. The molecules are then accelerated in an electric field and, depending on their mass, travel faster or slower and so hit a detector at different times, hence the term TOF. This results in a peak pattern, the mass spectrum, which is compared with a spectrum database, allowing its identification in a matter of minutes [170].

Proteomics-targeted MALDI-TOF MS has already become an accurate identification tool in bacteriology and is now being applied to the identification of filamentous fungi at speeds relevant for fungal diagnostic procedures [171]. Following the first report describing the characterization of spores from four Aspergillus species by MALDI-TOF MS [172], mass spectral fingerprints can now achieve unambiguous discrimination of members of the genus Aspergillus at the species level, with a $95 \%$ accuracy at the strain level [173]. Another report used a database of the reference spectra from 28 clinically relevant Aspergillus species to identify correctly $138 / 140$ isolates, with no misidentification [174]. This is similar to other studies that were able to identify 91/94 [175] and 160/162 [176] Aspergillus isolates correctly at the species level. Another study reported the detailed proteomic phenotyping of 230 filamentous fungi isolated from immunocompromised patients. These comprised ten genera (Aspergillus, Emericella, Fusarium, Geosmithia, Neosartorya, Penicillium, Pseudallescheria, Scedosporium, Talaromyces, Fomitopsis) and were correlated to 22 laboratory-adapted reference MALDI-TOF MS proteomic fingerprints. This not only goes some way towards a redefinition of phenotypes according to proteomic traits of fungal pathogens, allowing fungal identification in cases where more traditional classifications are inadequate [177] but may also lead to accurate prediction of drug resistance.

Most problems with identification are due to absence, mistakes or incomplete reference spectra as well as differences in sample handling procedures [169]. Hence, reliable identification of organisms by this technique is only possible if the strains used to construct the reference spectral database have been carefully selected and identified by a reliable method such as the sequencing of the ITS region [178]. This points to another problem: the ongoing genome-wide sequencing of fungi is leading to changes in fungal classification that can cause confusion and disagreement between laboratories [179], although of course in the longer term the identification of cryptic species within the Aspergillus species complex could help with more accurate prognoses, antifungal susceptibility profiles and so drive appropriate therapies tailored to the specific pathogen [180]. The identification and classification of fungi also requires dedicated software to enable comparisons with the reference spectra [180]. Careful calibration of the machine and selection of adequate internal standards are also required, in particular when intraspecies characterization is needed. Geographic variation in the genotypic and phenotypic expression may require region-specific calibration and preparation of locally adapted databases [181]. Finally, care must be taken always to use the culture medium that has been used to construct the reference spectra [182]. Unfortunately, at the moment, very few reference spectra are included in the database of commercially available MALDI-TOF MS systems and individual research groups use their own. Furthermore, they also use their own, not always completely documented, sample preparation techniques and this lack of standardized extraction protocols is the cause of much of the variability in the reported reproducibility of this technology [183].

Identification of fungal pathogens from subcultures is not ideal, as this takes time, even if the MS itself is very rapid. Furthermore, the technique is cultivation-dependent as growth must be obtained in order to be able to perform the analyses. Direct analysis of clinical samples would increase the usefulness of MS. Although one report describing its use for detection of fungemia in blood culture found it to be unreliable [184], this is probably associated with experimental procedures and a second report describes a detailed optimization of protocols, which allowed identification of Candida species [12], suggesting that further technical developments will help solve that problem.

The flexibility that allows MS to analyze all kinds of molecules under optimal conditions makes it likely that it can soon be used for the detection of Aspergillus-specific metabolites and nucleic acids [185]. There is an interesting perspective on the potential detection of nonribosomal cyclic peptides and depsipeptides by MS as highly specific fungal markers [186] and a recent report describes the derivatization of gliotoxin [187], which is produced by nonribosomal peptide synthesis, to make it detectable by MALDI-TOF MS. The potential of MALDI-TOF using metabolomic approaches is demonstrated by the successful profiling of low-molecular mass volatile compounds in the headspace (the air or empty space left above the contents in a sealed container) of C. albicans urine suspensions by another MS method, proton-transfer reaction MS [188]. MALDITOF instruments can record in excess of 10 spectra per second; since a mass spectrum provides many detection channels, a MALDI-TOF analysis is suitable for highthroughput, multichannel detection and quantitative analysis of DNA [189] and RNA [190]. Consequently, this method has become a powerful platform for the 


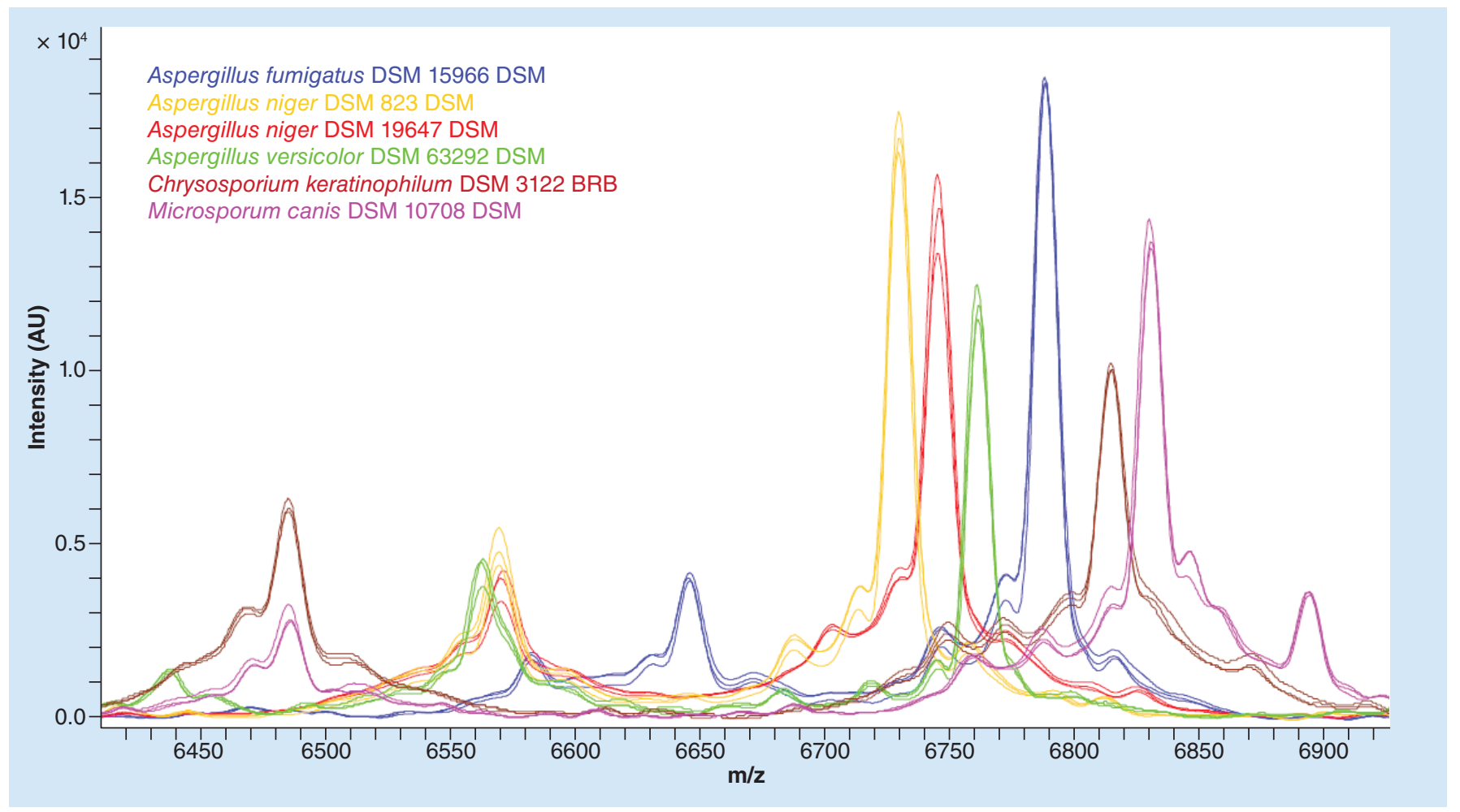

Figure 8. Matrix-assisted laser desorption ionization mass patterns demonstrating that three different genera, three different species within one genus, and two strains within one species can be distinguished.

Reproduced with permission from Bruker Daltonics GmbH (Germany).

Please see color figure at www.futuremedicine.com/doi/full/10.2217/bmm.13.129

study of nucleic acid sequence [191] and expression level changes [168] and holds tremendous potential, as yet untapped, for specific detection of fungal pathogens.

\section{Conclusion}

There are several nonculture-based biomarkers currently available for diagnosis of IA, with the most widely used GM and BDG having variable sensitivity and high false-positivity rates. An alternative, LFD-based approach immunodetection of an antigen expressed by actively growing Aspergilli holds considerable promise with BAL fluids, although its performance in serum is uncertain. Siderophore detection is also emerging as a potential strategy for diagnosis of IA. Hence, accurate diagnosis continues to rely on complementary diagnostic approaches, as test results must be interpreted in conjunction with a range of clinical indicators of infection $[1,9]$. Which combination will prove to be the most clinically useful remains a moot point, but one attractive combination is GM testing and PCR analysis [192,193], or a triple test involving GM, the LFD and PCR. For now, clinical decision-making is usually made on intuition and suspicion, rather than on hard evidence. While there are potential alternatives, none have yet been validated in clinical trials. PCRbased assays, useful in many other diagnostic settings, require a significant quality overhaul before they can be incorporated into EORTC/MSG diagnostic criteria and generate clinically relevant results. However, the steady addition of Aspergillus genomic sequences to the sequence database should help identify more discriminatory diagnostic markers for Aspergillus-associated infections, providing a strong incentive to continue optimizing and validating PCR-based assays. One way of overcoming many of the problems associated with detection of Aspergillus antigens and nucleic acids may be to combine the two approaches by using a PLA or PEA technology approach. MALDI-TOF MS is proving to be a fast, accurate and reliable tool for the identification of pathogenic fungi, although of course the general problem of obtaining positive cultures from clinical samples remains. The use of MS methods is still challenged by the high cost of instruments, but it is conceivable that once reference mass spectra have been expanded so that all clinically relevant species are included in mass spectrum databases, other culturedependent biochemical testing and differentiation assays will become obsolete.

\section{Future perspective}

The incidence of invasive fungal disease will continue to rise with the growing numbers of patients with an 
impaired immune state associated with the management of malignancy, organ transplantation, autoimmune and inflammatory conditions. This and the significant morbidity and mortality associated with this disease is resulting in an improved awareness of this problem and will accelerate the pursuit of robust, rapid, simple and cheap diagnostic procedures that allow the best practice in patient management. This is going to affect the availability of new biomarkers as well as new or improved methods for their earlier detection not just in blood or serum, but in BALs, urine and possibly exhaled breath. GM is likely to be used progressively with BALs, rather than with serum as its sensitivity is higher. The future role of the BDG assay is uncertain, although its high negative-predictive value may results in its use in carefully designed care pathways in specialist centers. There will be progress in the ability to diagnose with more accuracy lesions detected by CT scans and lateral flow devices and siderophore detection offer huge promise. The practical value of PCR remains to be determined, with the potential for detection of contamination a major issue; variants such as the PEA/PLA will potentially turn out to be more useful. Together, these innovations will gradually replace the more traditional diagnostic pro- cedures, although histopathology and culture-based methods will remain important methods for investigating the new species of pathogenic Aspergillus that continue to be discovered.

\section{Acknowledgements}

We are grateful to Melvyn Eydmann and Tim Linehan, Microbiology Department, Royal London Hospital, UK for permission to use the pictures of fungi in Figure 2 and to Bruker Daltonics GMBH, Germany, for permission to use their mass spectrum data shown in Figure 8

\section{Financial \& competing interests disclosure}

The proximity ligation assay results shown in Figure 1 were obtained using a grant from the Faculty Support Fund, Anglia Ruskin University, UK, as well as reagents donated by Mark Shannon, Life Technologies, San Francisco, CA, USA and Chris Thornton, University of Exeter, UK. SK Dolan is an IRC Scholar. The authors have no other relevant affiliations or financial involvement with any organization or entity with a financial interest in or financial conflict with the subject matter or materials discussed in the manuscript apart from those disclosed.

No writing assistance was utilized in the production of this manuscript.

\section{Executive summary}

Invasive aspergillosis

- Invasive aspergillosis (IA) is the most common infectious fungal cause of morbidity and mortality in immunocompromised individuals.

- Traditional clinical diagnostic methods are inadequate for early detection of infection and rely on invasive procedures. This has led to the widespread use of empirical antifungal therapy.

- There are some concerns regarding the sensitivity and specificity of galactomannan and 1,3 $\beta$-D-glucans, the two nonculturebased diagnostic assays recommended by the European Organisation for Research and Treatment of Cancer/Mycoses Study Group.

Alternative diagnostic procedures

- A new lateral flow device-based method detecting an extracellular glycoprotein antigen that is secreted only during active growth of the fungus promises to provide a convenient POC assay for the detection of IA.

- Nucleic acid-based tests, especially real-time PCR must become more consistent and reproducible before they can deliver clinically relevant results.

- Aspergillus-derived siderophores provide another novel target for potential biomarker detection in serum and urine, but have yet to be introduced into clinical use.

- Mass spectrometry also has tremendous potential that is as yet untapped for specific detection of fungal pathogens.

Future perspective

- Each approach has its own limitations and a combination of methods will be required to achieve optimal performance for the diagnosis of IA and subsequent appropriate patient management.

- Novel methods will gradually replace the more traditional diagnostic procedures, although these will remain important for investigating new species of pathogenic Aspergillus that continue to be discovered.

\section{References}

Papers of special note have been highlighted as:

- of interest

- of considerable interest

1 Perfect JR. Fungal diagnosis: how do we do it and can we do better? Curr. Med. Res. Opin. 29(Suppl. 4), 3-11 (2013).
2 Barnes RA. Directed therapy for fungal infections: focus on aspergillosis. J. Antimicrob. Chemother. 68(11), 2431-2434 (2013).

- Concise and up-to-date summary of therapeutic decisionmaking for invasive aspergillosis.

3 Bruno C, Minniti S, Vassanelli A, Pozzi-Mucelli R. Comparison of CT features of Aspergillus and bacterial 
pneumonia in severely neutropenic patients. J. Thorac. Imaging 22, 160-165 (2007).

4 Lass-Florl C, Follett SA, Moody A, Denning DW. Detection of Aspergillus in lung and other tissue samples using the MycAssay Aspergillus real-time PCR kit. Can. J. Microbiol. 57, 765-768 (2011)

5 Ascioglu S, Rex JH, de Pauw B et al. Defining opportunistic invasive fungal infections in immunocompromised patients with cancer and hematopoietic stem cell transplants: an international consensus. Clin. Infect. Dis. 34, 7-14 (2002).

6 De Pauw B, Walsh TJ, Donnelly JP et al. Revised definitions of invasive fungal disease from the European Organization for Research and Treatment of Cancer/Invasive Fungal Infections Cooperative Group and the National Institute of Allergy and Infectious Diseases Mycoses Study Group (EORTC/MSG) Consensus Group. Clin. Infect. Dis. 46, 1813-1821 (2008)

7 von Eiff M, Roos N, Schulten R, Hesse M, Zuhlsdorf M, van de Loo J. Pulmonary aspergillosis: early diagnosis improves survival. Respiration 62, 341-347 (1995).

8 Grace CJ, Lieberman J, Pierce K, Littenberg B. Usefulness of blood culture for hospitalized patients who are receiving antibiotic therapy. Clin. Infect. Dis. 32, 1651-1655 (2001).

9 White PL, Parr C, Thornton C, Barnes RA. Evaluation of real-time PCR, galactomannan enzyme-linked immunosorbent assay (ELISA), and a novel lateral-flow device for diagnosis of invasive aspergillosis. J. Clin. Microbiol. 51, 1510-1516 (2013).

10 Petrik M, Franssen GM, Haas H et al. Preclinical evaluation of two 68Ga-siderophores as potential radiopharmaceuticals for Aspergillus fumigatus infection imaging. Eur. J. Nucl. Med. Mol. Imaging 39, 1175-1183 (2012)

11 Johnson G, Nolan T, Bustin SA. Real-time quantitative PCR, pathogen detection and MIQE. Methods Mol. Biol. 943, 1-16 (2013)

12 Marinach-Patrice C, Fekkar A, Atanasova R et al. Rapid species diagnosis for invasive candidiasis using mass spectrometry. PLoS ONE 5, e8862 (2010)

13 Fredriksson S, Gullberg M, Jarvius J et al. Protein detection using proximity-dependent DNA ligation assays. Nat. Biotechnol. 20, 473-477 (2002)

14 Thornton CR. Development of an immunochromatographic lateral-flow device for rapid serodiagnosis of invasive aspergillosis. Clin. Vaccine Immunol. 15, 1095-1105 (2008).

-. Isolation of an antibody that is specific for actively growing Aspergillus and is used in a novel lateral flow device.

15 Latge JP. Aspergillus fumigatus and aspergillosis. Clin. Microbiol. Rev. 12, 310-350 (1999).

16 Perea S, Patterson TF. Invasive Aspergillus infections in hematologic malignancy patients. Semin. Respir. Infect. 17, 99-105 (2002).

17 Balloy V, Chignard M. The innate immune response to Aspergillus fumigatus. Microbes Infect. 11, 919-927 (2009).

18 Sheppard DC. Molecular mechanism of Aspergillus fumigatus adherence to host constituents. Curr. Opin. Microbiol. 14, 375-379 (2011).
19 Slobbe L, Polinder S, Doorduijn JK et al. Outcome and medical costs of patients with invasive aspergillosis and acute myelogenous leukemia-myelodysplastic syndrome treated with intensive chemotherapy: an observational study. Clin. Infect. Dis. 47, 1507-1512 (2008).

20 Ostrosky-Zeichner L. Invasive mycoses: diagnostic challenges. Am. J. Med. 125, S14-S24 (2012).

21 Balajee SA, Houbraken J, Verweij PE et al. Aspergillus species identification in the clinical setting. Stud. Mycol. 59, 39-46 (2007).

22 Torelli R, Sanguinetti M, Moody A et al. Diagnosis of invasive aspergillosis by a commercial real-time PCR assay for Aspergillus DNA in bronchoalveolar lavage fluid samples from high-risk patients compared to a galactomannan enzyme immunoassay. J. Clin. Microbiol. 49, 4273-4278 (2011).

23 Walsh TJ, Wissel MC, Grantham KJ et al. Molecular detection and species-specific identification of medically important Aspergillus species by real-time PCR in experimental invasive pulmonary aspergillosis. J. Clin. Microbiol. 49, 4150-4157 (2011).

24 Andreas S, Heindl S, Wattky C, Moller K, Ruchel R. Diagnosis of pulmonary aspergillosis using optical brighteners. Eur. Respir. J. 15, 407-411 (2000).

25 Barton RTC. Laboratory diagnosis of invasive aspergillosis: from diagnosis to prediction of outcome. Scientifica 2013, doi:10.1155/2013/459405 (2013) (Epub ahead of print).

26 Lass-Florl C, Speth C, Mayr A et al. Diagnosing and monitoring of invasive aspergillosis during antifungal therapy by polymerase chain reaction: an experimental study in mice. Diagn. Microbiol. Infect. Dis. 47, 569-572 (2003).

27 Herbrecht R, Natarajan-Ame S, Letscher-Bru V, Canuet M. Invasive pulmonary aspergillosis. Semin. Respir. Crit. Care Med. 25, 191-202 (2004).

28 Cuenca-Estrella M, Bassetti M, Lass-Florl C, Racil Z, Richardson M, Rogers TR. Detection and investigation of invasive mould disease. J. Antimicrob. Chemother. 66(Suppl. 1), i15-i24 (2011)

29 Cendejas-Bueno E, Gomez-Lopez A, Mellado E, RodriguezTudela JL, Cuenca-Estrella M. Identification of pathogenic rare yeast species in clinical samples: comparison between phenotypical and molecular methods. J. Clin. Microbiol. 48, 1895-1899 (2010).

30 Wang $\mathrm{H}, \mathrm{Xu} \mathrm{Z}$, Gao L, Hao B. A fungal phylogeny based on 82 complete genomes using the composition vector method. BMC Evol. Biol. 9, 195 (2009).

31 James TY, Kauff F, Schoch CL et al. Reconstructing the early evolution of Fungi using a six-gene phylogeny. Nature 443, $818-822$ (2006)

-. Detailed description of the use of molecular technologies to improve the reliability of fungal classification.

32 Yaguchi T, Horie Y, Tanaka R, Matsuzawa T, Ito J, Nishimura K. Molecular phylogenetics of multiple genes on Aspergillus section Fumigati isolated from clinical specimens in Japan. Nihon Ishinkin Gakkai Zasshi. 48, 37-46 (2007). 
33 Serrano R, Gusmao L, Amorim A, Araujo R. Rapid identification of Aspergillus fumigatus within the section Fumigati. BMC Microbiol. 11, 82 (2011)

34 Alcazar-Fuoli L, Mellado E, Alastruey-Izquierdo A, Cuenca-Estrella M, Rodriguez-Tudela JL. Aspergillus section Fumigati: antifungal susceptibility patterns and sequencebased identification. Antimicrob. Agents Chemother. 52 1244-1251 (2008).

35 Mikulska M, Furfaro E, Del Bono V et al. Galactomannan testing might be useful for early diagnosis of fusariosis. Diagn. Microbiol. Infect. Dis. 72, 367-369 (2012).

36 Engel J, Schmalhorst PS, Routier FH. Biosynthesis of the fungal cell wall polysaccharide galactomannan requires intraluminal GDP-mannose. J. Biol. Chem. 287, 44418-44424 (2012).

37 Morelle W, Bernard M, Debeaupuis JP, Buitrago M, Tabouret M, Latge JP. Galactomannoproteins of Aspergillus fumigatus. Eukaryot Cell. 4, 1308-1316 (2005).

38 Mennink-Kersten MA, Donnelly JP, Verweij PE. Detection of circulating galactomannan for the diagnosis and management of invasive aspergillosis. Lancet Infect. Dis. 4, 349-357 (2004).

39 Morton CO, Loeffler J, De Luca A et al. Dynamics of extracellular release of Aspergillus fumigatus DNA and galactomannan during growth in blood and serum. J. Med. Microbiol. 59, 408-413 (2010).

40 Hope WW, Kruhlak MJ, Lyman CA et al. Pathogenesis of Aspergillus fumigatus and the kinetics of galactomannan in an in vitro model of early invasive pulmonary aspergillosis: implications for antifungal therapy. J. Infect. Dis. 195, 455-466 (2007).

41 Franquet T, Muller NL, Gimenez A, Guembe P, de La Torre J, Bague S. Spectrum of pulmonary aspergillosis: histologic, clinical, and radiologic findings. Radiographics 21, 825-837 (2001)

42 Greene RE, Schlamm HT, Oestmann JW et al. Imaging findings in acute invasive pulmonary aspergillosis: clinical significance of the halo sign. Clin. Infect. Dis. 44, 373-379 (2007).

43 Verweij PE, Weemaes CM, Curfs JH, Bretagne S, Meis JF. Failure to detect circulating Aspergillus markers in a patient with chronic granulomatous disease and invasive aspergillosis. J. Clin. Microbiol. 38, 3900-3901 (2000).

44 Wheat LJ. Rapid diagnosis of invasive aspergillosis by antigen detection. Transpl. Infect. Dis. 5, 158-166 (2003).

45 Verweij PE, Latge JP, Rijs AJ et al. Comparison of antigen detection and PCR assay using bronchoalveolar lavage fluid for diagnosing invasive pulmonary aspergillosis in patients receiving treatment for hematological malignancies. J. Clin. Microbiol. 33, 3150-3153 (1995).

46 Patterson TF. Clinical utility and development of biomarkers in invasive aspergillosis. Trans. Am. Clin. Climatol. Assoc. 122, 174-183 (2011).

47 Hachem RY, Kontoyiannis DP, Chemaly RF, Jiang Y, Reitze $\mathrm{R}$, Raad I. Utility of galactomannan enzyme immunoassay and $(1,3)$ beta-D-glucan in diagnosis of invasive fungal infections: low sensitivity for Aspergillus fumigatus infection in hematologic malignancy patients. J. Clin. Microbiol. 47, 129-133 (2009).

48 Giacchino M, Chiapello N, Bezzio S et al. Aspergillus galactomannan enzyme-linked immunosorbent assay crossreactivity caused by invasive Geotrichum capitatum. J. Clin. Microbiol. 44, 3432-3434 (2006).

49 Vergidis P, Walker RC, Kaul DR et al. False-positive Aspergillus galactomannan assay in solid organ transplant recipients with histoplasmosis. Transpl. Infect. Dis. 14, 213-217 (2012).

50 Dalle F, Charles PE, Blanc K et al. Cryptococcus neoformans galactoxylomannan contains an epitope(s) that is crossreactive with Aspergillus galactomannan. J. Clin. Microbiol. 43, 2929-2931 (2005).

51 Boonsarngsuk V, Niyompattama A, Teosirimongkol C, Sriwanichrak K. False-positive serum and bronchoalveolar lavage Aspergillus galactomannan assays caused by different antibiotics. Scand. J. Infect. Dis. 42, 461-468 (2010).

52 Gerlinger MP, Rousselot P, Rigaudeau S et al. False positive galactomannan Platelia due to piperacillin-tazobactam. Med. Mal. Infect. 42, 10-14 (2012).

53 Mikulska M, Furfaro E, Del Bono V et al. Piperacillin/ tazobactam (Tazocin) seems to be no longer responsible for false-positive results of the galactomannan assay. J. Antimicrob. Chemother. 67, 1746-1748 (2012).

54 Orlopp K, von Lilienfeld-Toal M, Marklein G et al. False positivity of the Aspergillus galactomannan Platelia ELISA because of piperacillin/tazobactam treatment: does it represent a clinical problem? J. Antimicrob. Chemother. 62, 1109-1112 (2008).

55 Pfeiffer CD, Fine JP, Safdar N. Diagnosis of invasive aspergillosis using a galactomannan assay: a meta-analysis. Clin. Infect. Dis. 42, 1417-1427 (2006).

56 Leeflang MM, Debets-Ossenkopp YJ, Visser CE et al. Galactomannan detection for invasive aspergillosis in immunocompromized patients. Cochrane Database Syst. Rev. 4, CD007394 (2008).

57 Sun WK, Zhang F, Xu XY, Shen YY, Shi Y. A systematic review of the accuracy of diagnostic test of serum galactomannan antigen detection for invasive aspergillosis. Zhonghua Jie He He Hu Xi Za Zhi. 33, 758-765 (2010).

58 Marr KA, Laverdiere M, Gugel A, Leisenring W. Antifungal therapy decreases sensitivity of the Aspergillus galactomannan enzyme immunoassay. Clin. Infect. Dis. 40, 1762-1769 (2005).

59 Cordonnier C, Botterel F, Ben Amor R et al. Correlation between galactomannan antigen levels in serum and neutrophil counts in haematological patients with invasive aspergillosis. Clin. Microbiol. Infect. 15, 81-86 (2009).

60 Upton A, Gugel A, Leisenring W et al. Reproducibility of low galactomannan enzyme immunoassay index values tested in multiple laboratories. J. Clin. Microbiol. 43, 4796-4800 (2005).

61 Pereira CN, Del Nero G, Lacaz CS, Machado CM. The contribution of galactomannan detection in the diagnosis of invasive aspergillosis in bone marrow transplant recipients. Mycopathologia 159, 487-493 (2005). 
Oren I, Avidor I, Sprecher H. Lack of intra-laboratory reproducibility in using Platelia Aspergillus enzyme immunoassay test for detection of Aspergillus galactomannan antigen [letter]. Transpl. Infect. Dis. 14(1), 107-109 (2014). laboratory reproducibility in using Platelia Aspergillus enzyme immunoassay test for detection of Aspergillus galactomannan antigen. Transpl. Infect. Dis. 14, 218-219 (2012).

Johnson GL, Sarker SJ, Hill Ket al. Significant decline in galactomannan signal during storage of clinical serum samples. Int. J. Mol Sci. 14, 12970-12977 (2013).

65 Klont RR, Mennink-Kersten MA, Verweij PE. Utility of Aspergillus antigen detection in specimens other than serum specimens. Clin. Infect. Dis. 39, 1467-1474 (2004).

66 Becker MJ, Lugtenburg EJ, Cornelissen JJ, Van Der Schee C, Hoogsteden HC, De Marie S. Galactomannan detection in computerized tomography-based broncho-alveolar lavage fluid and serum in haematological patients at risk for invasive pulmonary aspergillosis. Br. J. Haematol. 121, 448-457 (2003).

67 Wheat LJ, Walsh TJ. Diagnosis of invasive aspergillosis by galactomannan antigenemia detection using an enzyme immunoassay. Eur. J. Clin. Microbiol. Infect. Dis. 27, 245-251 (2008).

68 Vallor AC, Kirkpatrick WR, Najvar LK et al. Assessment of Aspergillus fumigatus burden in pulmonary tissue of guinea pigs by quantitative PCR, galactomannan enzyme immunoassay, and quantitative culture. Antimicrob. Agents Chemother. 52, 2593-2598 (2008).

69 Musher B, Fredricks D, Leisenring W, Balajee SA, Smith C, Marr KA. Aspergillus galactomannan enzyme immunoassay and quantitative PCR for diagnosis of invasive aspergillosis with bronchoalveolar lavage fluid. J. Clin. Microbiol. 42, 5517-5522 (2004)

70 Clancy CJ, Jaber RA, Leather HL et al. Bronchoalveolar lavage galactomannan in diagnosis of invasive pulmonary aspergillosis among solid-organ transplant recipients. J. Clin. Microbiol. 45, 1759-1765 (2007).

71 Bergeron A, Belle A, Sulahian A et al. Contribution of galactomannan antigen detection in BAL to the diagnosis of invasive pulmonary aspergillosis in patients with hematologic malignancies. Chest 137, 410-415 (2010).

72 He H, Ding L, Sun B, Li F, Zhan Q. Role of galactomannan determinations in bronchoalveolar lavage fluid samples from critically ill patients with chronic obstructive pulmonary disease for the diagnosis of invasive pulmonary aspergillosis: a prospective study. Crit. Care 16, R138 (2012).

73 Izumikawa K, Yamamoto Y, Mihara T et al. Bronchoalveolar lavage galactomannan for the diagnosis of chronic pulmonary aspergillosis. Med. Mycol. 50, 811-817 (2012).

74 Zhang XB, Chen GP, Lin QC, Lin X, Zhang HY, Wang JH. Bronchoalveolar lavage fluid galactomannan detection for diagnosis of invasive pulmonary aspergillosis in chronic obstructive pulmonary disease. Med. Mycol. 51(7), 688-695 (2013).

75 Acosta J, Catalan M, del Palacio-Perez-Medel A et al. A prospective comparison of galactomannan in bronchoalveolar lavage fluid for the diagnosis of pulmonary invasive aspergillosis in medical patients under intensive care: comparison with the diagnostic performance of galactomannan and of (1-> 3)-beta-D-glucan chromogenic assay in serum samples. Clin. Microbiol. Infect. 17, 1053-1060 (2011)

76 Nguyen MH, Jaber R, Leather HL et al. Use of bronchoalveolar lavage to detect galactomannan for diagnosis of pulmonary aspergillosis among nonimmunocompromised hosts. J. Clin. Microbiol. 45, 2787-2792 (2007)

77 Park SY, Lee SO, Choi SH et al. Aspergillus galactomannan antigen assay in bronchoalveolar lavage fluid for diagnosis of invasive pulmonary aspergillosis. J. Infect. 61, 492-498 (2010)

78 Tabarsi P, Soraghi A, Marjani M et al. Comparison of serum and bronchoalveolar lavage galactomannan in diagnosing invasive aspergillosis in solid-organ transplant recipients. Exp. Clin. Transplant. 10, 278-281 (2012).

79 Reinwald M, Spiess B, Heinz WJ et al. Diagnosing pulmonary aspergillosis in patients with hematological malignancies: a multicenter prospective evaluation of an Aspergillus PCR assay and a galactomannan ELISA in bronchoalveolar lavage samples. Eur. J. Haematol. 89, 120-127 (2012).

80 D'Haese J, Theunissen K, Vermeulen E et al. Detection of galactomannan in bronchoalveolar lavage fluid samples of patients at risk for invasive pulmonary aspergillosis: analytical and clinical validity. J. Clin. Microbiol. 50, 1258-1263 (2012).

81 Desai R, Ross LA, Hoffman JA. The role of bronchoalveolar lavage galactomannan in the diagnosis of pediatric invasive aspergillosis. Pediatr. Infect. Dis. J. 28, 283-286 (2009).

82 Maertens J, Maertens V, Theunissen K et al. Bronchoalveolar lavage fluid galactomannan for the diagnosis of invasive pulmonary aspergillosis in patients with hematologic diseases. Clin. Infect. Dis. 49, 1688-1693 (2009).

83 Danpornprasert P, Foongladda S, Tscheikuna J. Impact of bronchoalveolar lavage galactomannan on the outcome of patients at risk for invasive pulmonary aspergillosis. J. Med. Assoc. Thai. 93(Suppl. 1), S86-S93 (2010).

84 Hsu LY, Ding Y, Phua J et al. Galactomannan testing of bronchoalveolar lavage fluid is useful for diagnosis of invasive pulmonary aspergillosis in hematology patients. BMC Infect. Dis. 10, 44 (2010)

85 Pasqualotto AC, Xavier MO, Sanchez LB et al. Diagnosis of invasive aspergillosis in lung transplant recipients by detection of galactomannan in the bronchoalveolar lavage fluid. Transplantation 90, 306-311 (2010).

86 Luong ML, Filion C, Labbe AC et al. Clinical utility and prognostic value of bronchoalveolar lavage galactomannan in patients with hematologic malignancies. Diagn. Microbiol. Infect. Dis. 68, 132-139 (2010).

87 Zou M, Tang L, Zhao S et al. Systematic review and metaanalysis of detecting galactomannan in bronchoalveolar lavage fluid for diagnosing invasive aspergillosis. PLoS ONE 7, e43347 (2012)

88 Racil Z, Kocmanova I, Toskova M et al. Galactomannan detection in bronchoalveolar lavage fluid for the diagnosis of invasive aspergillosis in patients with hematological diseases- 
the role of factors affecting assay performance. Int. J. Infect. Dis. 15, e874-e881 (2011).

89 Husain S, Clancy CJ, Nguyen MH et al. Performance characteristics of the platelia Aspergillus enzyme immunoassay for detection of Aspergillus galactomannan antigen in bronchoalveolar lavage fluid. Clin. Vaccine Immunol. 15, 1760-1763 (2008).

90 Brownback KR, Pitts LR, Simpson SQ. Utility of galactomannan antigen detection in bronchoalveolar lavage fluid in immunocompromised patients. Mycoses 56(5), 552-558 (2013).

91 Garcia RS, Wheat LJ, Cook AK, Kirsch EJ, Sykes JE. Sensitivity and specificity of a blood and urine galactomannan antigen assay for diagnosis of systemic aspergillosis in dogs. J. Vet. Intern. Med. 26, 911-919 (2012).

92 Dufresne SF, Datta K, Li X et al. Detection of urinary excreted fungal galactomannan-like antigens for diagnosis of invasive aspergillosis. PLoS ONE 7, e42736 (2012).

93 Marty FM, Koo S. Role of (1->3)-beta-D-glucan in the diagnosis of invasive aspergillosis. Med. Mycol. 47(Suppl. 1), S233-S240 (2009).

94 Lehmann PF, Reiss E. Invasive aspergillosis: antiserum for circulating antigen produced after immunization with serum from infected rabbits. Infect. Immun. 20, 570-572 (1978).

95 Odabasi Z, Mattiuzzi G, Estey E et al. Beta-D-glucan as a diagnostic adjunct for invasive fungal infections: validation, cutoff development, and performance in patients with acute myelogenous leukemia and myelodysplastic syndrome. Clin. Infect. Dis. 39, 199-205 (2004).

96 Senn L, Robinson JO, Schmidt S et al. 1,3-beta-D-glucan antigenemia for early diagnosis of invasive fungal infections in neutropenic patients with acute leukemia. Clin. Infect. Dis. 46, 878-885 (2008).

97 Karageorgopoulos DE, Vouloumanou EK, Ntziora F, Michalopoulos A, Rafailidis PI, Falagas ME. Beta-D-glucan assay for the diagnosis of invasive fungal infections: a metaanalysis. Clin. Infect. Dis. 52, 750-770 (2011).

98 Onishi A, Sugiyama D, Kogata Y et al. Diagnostic accuracy of serum 1,3-beta-D-glucan for Pneumocystis jiroveci pneumonia, invasive candidiasis, and invasive aspergillosis: systematic review and meta-analysis. J. Clin. Microbiol. 50, 7-15 (2012).

99 Racil Z, Kocmanova I, Lengerova M et al. Difficulties in using 1,3-\{beta\}-D-glucan as the screening test for the early diagnosis of invasive fungal infections in patients with haematological malignancies - high frequency of falsepositive results and their analysis. J. Med. Microbiol. 59, 1016-1022 (2010).

100 Fisher BT. The role of biomarkers for diagnosis of and therapeutic decisions related to invasive aspergillosis in children. Curr. Fungal Infect. Rep. 7, 7-14 (2013)

101 Schrettl M, Carberry S, Kavanagh K et al. Self-protection against gliotoxin - a component of the gliotoxin biosynthetic cluster, GliT, completely protects Aspergillus fumigatus against exogenous gliotoxin. PLoS Pathog. 6, e1000952 (2010).
102 Shi LN, Li FQ, Lu JF et al. Antibody specific to thioredoxin reductase as a new biomarker for serodiagnosis of invasive aspergillosis in non-neutropenic patients. Clin. Chim. Acta 413, 938-943 (2012).

103 Hao W, Pan YX, Ding YQ et al. Well-characterized monoclonal antibodies against cell wall antigen of Aspergillus species improve immunoassay specificity and sensitivity. Clin. Vaccine Immunol. 15, 194-202 (2008).

104 Wiederhold NP, Thornton CR, Najvar LK, Kirkpatrick WR, Bocanegra R, Patterson TF. Comparison of lateral flow technology and galactomannan and (1->3)-beta-D-glucan assays for detection of invasive pulmonary aspergillosis. Clin. Vaccine Immunol. 16, 1844-1846 (2009).

105 Wiederhold NP, Najvar LK, Bocanegra R, Kirkpatrick WR, Patterson TF, Thornton CR. Interlaboratory and interstudy reproducibility of a novel lateral-flow device and influence of antifungal therapy on detection of invasive pulmonary aspergillosis. J. Clin. Microbiol. 51, 459-465 (2013).

106 Thornton C, Johnson G, Agrawal S. Detection of invasive pulmonary aspergillosis in haematological malignancy patients by using lateral-flow technology. J. Vis. Exp. 61, pii: 3721 (2012).

107 Schutte M, Thullier P, Pelat T et al. Identification of a putative Crf splice variant and generation of recombinant antibodies for the specific detection of Aspergillus fumigatus. PLoS ONE 4, e6625 (2009).

108 Schwienbacher M, Israel L, Heesemann J, Ebel F. Asp f6, an Aspergillus allergen specifically recognized by IgE from patients with allergic bronchopulmonary aspergillosis, is differentially expressed during germination. Allergy 60, 1430-1435 (2005).

109 Puri A, Ahmad A, Panda BP. Development of an HPTLCbased diagnostic method for invasive aspergillosis. Biomed. Chromatogr. 24, 887-892 (2010).

110 Domingo MP, Colmenarejo C, Martinez-Lostao L et al. Bis(methyl)gliotoxin proves to be a more stable and reliable marker for invasive aspergillosis than gliotoxin and suitable for use in diagnosis. Diagn. Microbiol. Infect. Dis. 73, 57-64 (2012).

111 Kumar A, Ahmed R, Singh PK, Shukla PK. Identification of virulence factors and diagnostic markers using immunosecretome of Aspergillus fumigatus. J. Proteomics 74, 1104-1112 (2011).

112 Neustadt M, Costina V, Kupfahl C et al. Characterization and identification of proteases secreted by Aspergillus fumigatus using free flow electrophoresis and MS. Electrophoresis 30, 2142-2150 (2009).

113 Haas H. Iron - a key nexus in the virulence of Aspergillus fumigatus. Front. Microbiol. 3, 28 (2012).

114 Hider RC, Kong X. Chemistry and biology of siderophores. Nat. Prod. Rep. 27, 637-657 (2010).

115 Hissen AH, Wan AN, Warwas ML, Pinto LJ, Moore MM. The Aspergillus fumigatus siderophore biosynthetic gene sidA, encoding L-ornithine $\mathrm{N} 5$-oxygenase, is required for virulence. Infect. Immun. 73, 5493-5503 (2005).

116 Doyle JM, Walshe, K. Gordon N, Kavanagh K, Gallagher L. Method for detecting infections. EP-2012/059133 (2012). http://patentscope.wipo.int/search/en/detail.jsf?docId=WO20 $12156452 \& \mathrm{recNum}=265 \& \operatorname{maxRec}=98863 \&$ office $=\&$ prevFil ter $=\&$ sortOption $=\&$ queryString $=\&$ tab $=$ PCT + Biblio 
117 Horvath I, Hunt J, Barnes PJ et al. Exhaled breath condensate: methodological recommendations and unresolved questions. Eur. Respir. J. 26, 523-548 (2005).

118 Liu J, Thomas PS. Exhaled breath condensate as a method of sampling airway nitric oxide and other markers of inflammation. Med. Sci. Monit. 11, MT53-MT62 (2005).

119 Chambers ST, Bhandari S, Scott-Thomas A, Syhre M. Novel diagnostics: progress toward a breath test for invasive Aspergillus fumigatus. Med. Mycol. 49(Suppl. 1), S54-S61 (2011).

120 Chambers ST, Syhre M, Murdoch DR, McCartin F, Epton MJ. Detection of 2-pentylfuran in the breath of patients with Aspergillus fumigatus. Med. Mycol. 47, 468-476 (2009).

121 Chambers ST, Scott-Thomas A, Epton M. Developments in novel breath tests for bacterial and fungal pulmonary infection. Curr. Opin. Pulm. Med. 18, 228-232 (2012).

122 Carpagnano GE, Foschino-Barbaro MP, Mule G et al. 3p microsatellite alterations in exhaled breath condensate from patients with non-small cell lung cancer. Am. J. Respir. Crit. Care Med. 172, 738-744 (2005).

123 Yang Ai SS, Hsu K, Herbert C et al. Mitochondrial DNA mutations in exhaled breath condensate of patients with lung cancer. Respir. Med. 107(6), 911-918 (2013).

124 Chikasue K, Kimura M, Ikeda K et al. Detection of torque teno virus DNA in exhaled breath by polymerase chain reaction. Acta Med. Okayama 66, 387-397 (2012).

$125 \mathrm{Xu}$ Z, Shen F, Li X et al. Molecular and microscopic analysis of bacteria and viruses in exhaled breath collected using a simple impaction and condensing method. PLoS ONE 7, e41137 (2012)

126 Zakharkina T, Koczulla AR, Mardanova O, Hattesohl A, Bals R. Detection of microorganisms in exhaled breath condensate during acute exacerbations of COPD. Respirology 16, 932-938 (2011).

127 Jain R, Schriever CA, Danziger LH, Cho SH, Rubinstein I. The IS6110 repetitive DNA element of Mycobacterium tuberculosis is not detected in exhaled breath condensate of patients with active pulmonary tuberculosis. Respiration 74 , 329-333 (2007).

128 St George K, Fuschino ME, Mokhiber K, Triner W, Spivack SD. Exhaled breath condensate appears to be an unsuitable specimen type for the detection of influenza viruses with nucleic acid-based methods. J. Virol. Methods 163, 144-146 (2010).

129 Costa C, Bucca C, Bergallo M, Solidoro P, Rolla G, Cavallo R Unsuitability of exhaled breath condensate for the detection of herpesviruses DNA in the respiratory tract. J. Virol. Methods 173, 384-386 (2011).

130 Houspie L, De Coster S, Keyaerts E et al. Exhaled breath condensate sampling is not a new method for detection of respiratory viruses. Virol. J. 8, 98 (2011).

131 Goldoni M, Corradi M, Mozzoni P et al. Concentration of exhaled breath condensate biomarkers after fractionated collection based on exhaled $\mathrm{CO}_{2}$ signal. J. Breath. Res. 7, 017101 (2013).

132 Doffman SR, Griffiths LJ, Athorn GR et al. Galactomannan detection in exhaled breath condensate of neutropenic patients with suspected invasive pulmonary aspergillosis. Thorax 62, S126 (2007).

133 The role of galactomannan in exhaled breath condensate in detecting pulmonary aspergillosis in patients with exacerbated COPD.

www.ersnetsecure.org/public/prg_congres.abstract?ww_i_ presentation $=55648$

134 Bustin SA, Murphy J, Kessler HH. Amplification and detection methods. In: Molecular Diagnostics of Infectious Diseases (2nd Revised Edition). Kessler HH (Ed.). De Gruyter, Berlin, Germany, 53-68 (2012).

135 Loeffler J, Hebart H, Cox P, Flues N, Schumacher U, Einsele H. Nucleic acid sequence-based amplification of Aspergillus RNA in blood samples. J. Clin. Microbiol. 39, 1626-1629 (2001).

136 Yoo JH, Choi SM, Lee DG et al. Comparison of the real-time nucleic acid sequence-based amplification (RTiNASBA) with conventional NASBA, and galactomannan assay for the diagnosis of invasive aspergillosis. J. Korean Med. Sci. 22, 672-676 (2007).

137 Zhao Y, Park S, Kreiswirth BN et al. Rapid real-time nucleic acid sequence-based amplification-molecular beacon platform to detect fungal and bacterial bloodstream infections. J. Clin. Microbiol. 47, 2067-2078 (2009).

138 Zhao Y, Perlin DS. Quantitative detection of Aspergillus spp. by real-time nucleic acid sequence-based amplification. Methods Mol. Biol. 968, 83-92 (2013).

139 Spiess B, Seifarth W, Hummel M et al. DNA microarraybased detection and identification of fungal pathogens in clinical samples from neutropenic patients. J. Clin. Microbiol. 45, 3743-3753 (2007).

140 Simitsopoulou M, Roilides E, Georgiadou E, Paliogianni F, Walsh TJ. Differential transcriptional profiles induced by amphotericin B formulations on human monocytes during response to hyphae of Aspergillus fumigatus. Med. Mycol. 49, 176-185 (2011).

141 Dhesi Z, Herbst S, Armstrong-James D. Transcript profiling of the murine immune response to invasive aspergillosis. Methods Mol. Biol. 845, 435-444 (2012).

142 Bustin SA, Dorudi S. The value of microarray techniques for quantitative gene profiling in molecular diagnostics. Trends Mol. Med. 8, 269-272 (2002).

143 Rosa C, Araujo R, Rodrigues AG, Pinto-de-Sousa MI, Pina-Vaz C. Detection of Aspergillus species in BACTEC blood cultures. J. Med. Microbiol. 60, 1467-1471 (2011).

144 White PL, Mengoli C, Bretagne S et al. Evaluation of Aspergillus PCR protocols for testing serum specimens. J. Clin. Microbiol. 49, 3842-3848 (2011).

145 White PL, Perry MD, Loeffler J et al. Critical stages of extracting DNA from Aspergillus fumigatus in whole-blood specimens. J. Clin. Microbiol. 48, 3753-3755 (2010).

146 Lengerova M, Kocmanova I, Racil Z et al. Detection and measurement of fungal burden in a guinea pig model of invasive pulmonary aspergillosis by novel quantitative nested real-time PCR compared with galactomannan and (1,3)-beta-D-glucan detection. J. Clin. Microbiol. 50, 602-608 (2012). 
147 Hadrich I, Mary C, Makni F et al. Comparison of PCRELISA and real-time PCR for invasive aspergillosis diagnosis in patients with hematological malignancies. Med. Mycol. 49, 489-494 (2011).

148 Bustin SA, Mueller R. Real-time reverse transcription PCR (qRT-PCR) and its potential use in clinical diagnosis. Clin. Sci. (Lond.) 109, 365-379 (2005).

149 Johnson GL, Bibby DF, Wong S, Agrawal SG, Bustin SA. A MIQE-compliant real-time PCR assay for Aspergillus detection. PLoS ONE 7, e40022 (2012).

150 Morton CO, Clemons KV, Springer J et al. Real-time PCR and quantitative culture for monitoring of experimental Aspergillus fumigatus intracranial infection in neutropenic mice. J. Med. Microbiol. 60, 913-919 (2011).

151 Bacich DJ, Sobek KM, Cummings JL, Atwood AA, O’Keefe DS. False negative results from using common PCR reagents. BMC Res. Notes 4, 457 (2011).

152 Abad-Diaz-De-Cerio A, Fernandez-Molina JV, RamirezGarcia A et al. The aspHS gene as a new target for detecting Aspergillus fumigatus during infections by quantitative realtime PCR. Med. Mycol. 51(5), 545-554 (2013).

153 Khot PD, Fredricks DN. PCR-based diagnosis of human fungal infections. Expert Rev. Anti Infect. Ther. 7, 1201-1221 (2009).

- Perceptive review of the role of PCR in clinical diagnostics.

154 Donnelly JP. Polymerase chain reaction for diagnosing invasive aspergillosis: getting closer but still a ways to go. Clin. Infect. Dis. 42, 487-489 (2006).

155 Mengoli C, Cruciani M, Barnes RA, Loeffler J, Donnelly JP. Use of PCR for diagnosis of invasive aspergillosis: systematic review and meta-analysis. Lancet Infect. Dis. 9, 89-96 (2009).

156 Avni T, Levy I, Sprecher H, Yahav D, Leibovici L, Paul M. Diagnostic accuracy of PCR alone compared to galactomannan in bronchoalveolar lavage fluid for diagnosis of invasive pulmonary aspergillosis: a systematic review. J. Clin. Microbiol. 50, 3652-3658 (2012).

157 Armenian SH, Nash KA, Kapoor N et al. Prospective monitoring for invasive aspergillosis using galactomannan and polymerase chain reaction in high risk pediatric patients. J. Pediatr. Hematol. Oncol. 31, 920-926 (2009).

158 Springer J, Schlossnagel H, Heinz W et al. A novel extraction method combining plasma with a whole-blood fraction shows excellent sensitivity and reproducibility for patients at high risk for invasive aspergillosis. J. Clin. Microbiol. 50, 2585-2591 (2012).

159 Millon L, Grenouillet F, Legrand F et al. Ribosomal and mitochondrial DNA target for real-time PCR diagnosis of invasive aspergillosis. J. Clin. Microbiol. 49, 1058-1063 (2011).

160 Lopes da Silva R, Ribeiro P, Abreu N et al. Early diagnosis of invasive aspergillosis in neutropenic patients. Comparison between serum galactomannan and polymerase chain reaction. Clin. Med. Insights Oncol. 4, 81-88 (2010).

161 Hummel M, Spiess B, Roder J et al. Detection of Aspergillus DNA by a nested PCR assay is able to improve the diagnosis of invasive aspergillosis in paediatric patients. J. Med. Microbiol. 58, 1291-1297 (2009).
162 Badiee P, Alborzi A, Karimi M et al. Diagnostic potential of nested PCR, galactomannan EIA, and beta-D-glucan for invasive aspergillosis in pediatric patients. J. Infect. Dev. Ctries 6, 352-357 (2012).

163 Cuenca-Estrella M, Meije Y, Diaz-Pedroche C et al. Value of serial quantification of fungal DNA by a real-time PCRbased technique for early diagnosis of invasive aspergillosis in patients with febrile neutropenia. J. Clin. Microbiol. 47, 379-384 (2009).

164 Huggett J, Bustin SA. Standardisation and reporting for nucleic acid quantification. Accredit. Qual. Assur. 16, 399-405 (2011).

165 White PL, Bretagne S, Klingspor L et al. Aspergillus PCR: one step closer to standardization. J. Clin. Microbiol. 48, 1231-1240 (2010).

166 Bustin SA, Benes V, Garson JA et al. The MIQE guidelines: minimum information for publication of quantitative realtime PCR experiments. Clin. Chem. 55, 611-622 (2009).

-• Describes and justifies guidelines for the proper design and reporting of quantitative PCR assays; cited nearly 2000 times.

167 Bustin SA. Why the need for qPCR publication guidelines? - the case for MIQE. Methods 50, 217-226 (2010).

168 Gao X, Tan BH, Sugrue RJ, Tang K. MALDI mass spectrometry for nucleic acid analysis. Top. Curr. Chem. 331 , 55-77 (2013).

169 Bader O. MALDI-TOF-MS-based species identification and typing approaches in medical mycology. Proteomics 13 , 788-799 (2013).

170 Intelicato-Young J, Fox A. Mass spectrometry and tandem mass spectrometry characterization of protein patterns, protein markers and whole proteomes for pathogenic bacteria. J. Microbiol. Methods. 92, 381-386 (2013).

171 Croxatto A, Prod'hom G, Greub G. Applications of MALDI-TOF mass spectrometry in clinical diagnostic microbiology. FEMS Microbiol. Rev. 36, 380-407 (2012).

172 Li TY, Liu BH, Chen YC. Characterization of Aspergillus spores by matrix-assisted laser desorption/ionization time-offlight mass spectrometry. Rapid Commun. Mass Spectrom. 14, 2393-2400 (2000).

173 Hettick JM, Green BJ, Buskirk AD et al. Discrimination of Aspergillus isolates at the species and strain level by matrixassisted laser desorption/ionization time-of-flight mass spectrometry fingerprinting. Anal. Biochem. 380, 276-281 (2008).

174 Alanio A, Beretti JL, Dauphin B et al. Matrix-assisted laser desorption ionization time-of-flight mass spectrometry for fast and accurate identification of clinically relevant Aspergillus species. Clin. Microbiol. Infect. 17, 750-755 (2011).

175 De Carolis E, Posteraro B, Lass-Florl C et al. Species identification of Aspergillus, Fusarium and Mucorales with direct surface analysis by matrix-assisted laser desorption ionization time-of-flight mass spectrometry. Clin. Microbiol. Infect. 18, 475-484 (2012).

176 Bille E, Dauphin B, Leto J et al. MALDI-TOF MS Andromas strategy for the routine identification of bacteria, 
mycobacteria, yeasts, Aspergillus spp. and positive blood cultures. Clin. Microbiol. Infect. 18, 1117-1125 (2012).

177 Del Chierico F, Masotti A, Onori M et al. MALDI-TOF MS proteomic phenotyping of filamentous and other fungi from clinical origin. J. Proteomics 75, 3314-3330 (2012).

178 Marklein G, Josten M, Klanke U et al. Matrix-assisted laser desorption ionization-time of flight mass spectrometry for fast and reliable identification of clinical yeast isolates. J. Clin. Microbiol. 47, 2912-2917 (2009).

179 Ebersberger I, de Matos Simoes R, Kupczok A et al. A consistent phylogenetic backbone for the fungi. Mol. Biol. Evol. 29, 1319-1334 (2012).

180 Santos C, Paterson RR, Venancio A, Lima N. Filamentous fungal characterizations by matrix-assisted laser desorption/ ionization time-of-flight mass spectrometry. J. Appl. Microbiol. 108, 375-385 (2010).

181 Benagli C, Rossi V, Dolina M, Tonolla M, Petrini O. Matrix-assisted laser desorption ionization-time of flight mass spectrometry for the identification of clinically relevant bacteria. PLoS ONE 6, e16424 (2011).

182 Iriart X, Lavergne RA, Fillaux J et al. Routine identification of medical fungi by the new Vitek MS matrix-assisted laser desorption ionization-time of flight system with a new timeeffective strategy. J. Clin. Microbiol. 50, 2107-2110 (2012).

183 Giebel R, Worden C, Rust SM, Kleinheinz GT, Robbins M, Sandrin TR. Microbial fingerprinting using matrix-assisted laser desorption ionization time-of-flight mass spectrometry (MALDI-TOF MS) applications and challenges. Adv. Appl. Microbiol. 71, 149-184 (2010).

- Well-written and informative review summarizing the background and challenges associated with detection of fungi.

184 Ferreira L, Sanchez-Juanes F, Porras-Guerra I et al. Microorganisms direct identification from blood culture by matrix-assisted laser desorption/ionization time-of-flight mass spectrometry. Clin. Microbiol. Infect. 17, 546-551 (2011).

185 Limbach PA, Crain PF, McCloskey JA. Characterization of oligonucleotides and nucleic acids by mass spectrometry. Curr. Opin. Biotechnol. 6, 96-102 (1995).

186 Jegorov A, Hajduch M, Sulc M, Havlicek V. Nonribosomal cyclic peptides: specific markers of fungal infections. J. Mass Spectrom. 41, 563-576 (2006).

187 Davis C, Gordon N, Murphy S et al. Single-pot derivatisation strategy for enhanced gliotoxin detection by HPLC and MALDI-ToF mass spectrometry. Anal. Bioanal. Chem. 401, 2519-2529 (2011).

188 Zehm S, Schweinitz S, Wurzner R, Colvin HP, Rieder J. Detection of Candida albicans by mass spectrometric fingerprinting. Curr. Microbiol. 64, 271-275 (2012).

189 Gut IG. DNA analysis by MALDI-TOF mass spectrometry. Hum. Mutat. 23, 437-441 (2004).

190 Ding C, Lo YM. MALDI-TOF mass spectrometry for quantitative, specific, and sensitive analysis of DNA and RNA. Ann. NY Acad. Sci. 1075, 282-287 (2006).

191 Farkas DH, Miltgen NE, Stoerker J et al. The suitability of matrix assisted laser desorption/ionization time of flight mass spectrometry in a laboratory developed test using cystic fibrosis carrier screening as a model. J. Mol. Diagn. 12, 611-619 (2010).

192 Morrissey CO, Chen SC, Sorrell TC et al. Galactomannan and PCR versus culture and histology for directing use of antifungal treatment for invasive aspergillosis in high-risk haematology patients: a randomised controlled trial. Lancet Infect. Dis. 13(6), 519-528 (2013).

- Demonstration of the usefulness of combining two detection technologies for reduced use of empirical antifungal treatment. 
193 Rogers TR, Morton CO, Springer J et al. Combined real-time PCR and galactomannan surveillance improves diagnosis of invasive aspergillosis in high risk patients with haematological malignancies. Br. J. Haematol. 161, 517-524 (2013).

194 Bustin SA, Benes V, Garson J. The need for transparency and good practices in the qPCR literature. Nat. Methods 10, 1063-1067 (2013). 
